\title{
REVIEW
}

\section{Spatial scale and geographic context in benthic habitat mapping: review and future directions}

\author{
Vincent Lecours ${ }^{1,2, *}$, Rodolphe Devillers ${ }^{1,2}$, David C. Schneider ${ }^{3}$, \\ Vanessa L. Lucieer ${ }^{4}$, Craig J. Brown ${ }^{2,5}$, Evan N. Edinger ${ }^{2,6}$ \\ ${ }^{1}$ Marine Geomatics Research Lab, Department of Geography, Memorial University of Newfoundland, \\ Newfoundland and Labrador A1B 3X9, Canada \\ ${ }^{2}$ Marine Habitat Mapping Research Group, Department of Geography, Memorial University of Newfoundland, \\ Newfoundland and Labrador A1B 3X9, Canada \\ ${ }^{3}$ Department of Ocean Sciences, Memorial University of Newfoundland, Newfoundland and Labrador A1K 3E6, Canada \\ ${ }^{4}$ Institute for Marine and Antarctic Studies, University of Tasmania, Tasmania 7004, Australia \\ ${ }^{5}$ Nova Scotia Community College, Nova Scotia B2Y 0A5, Canada \\ ${ }^{6}$ Department of Biology, Memorial University of Newfoundland, Newfoundland and Labrador A1B 3X9, Canada
}

\begin{abstract}
Understanding the effects of scale is essential to the understanding of natural ecosystems, particularly in marine environments where sampling is more limited and sporadic than in terrestrial environments. Despite its recognized importance, scale is rarely considered in benthic habitat mapping studies. Lack of explicit statement of scale in the literature is an impediment to better characterization of seafloor pattern and process. This review paper highlights the importance of incorporating ecological scaling and geographical theories in benthic habitat mapping. It reviews notions of ecological scale and benthic habitat mapping, in addition to the way spatial scale influences patterns and processes in benthic habitats. We address how scale is represented in geographic data, how it influences their analysis, and consequently how it influences our understanding of seafloor ecosystems. We conclude that quantification of ecological processes at multiple scales using spatial statistics is needed to gain a better characterization of species-habitat relationships. We offer recommendations on more effective practices in benthic habitat mapping, including sampling that covers multiple spatial scales and that includes as many environmental variables as possible, adopting continuum-based habitat characterization approaches, using statistical analyses that consider the spatial nature of data, and explicit statement of the scale at which the research was conducted. We recommend a set of improved standards for defining benthic habitat. With these standards benthic habitats can be defined as 'areas of seabed that are (geo)statistically significantly different from their surroundings in terms of physical, chemical and biological characteristics, when observed at particular spatial and temporal scales'.
\end{abstract}

KEY WORDS: Spatial scale - Benthic habitat mapping - Multiscale - Spatial statistics · Marine ecology $\cdot$ Spatial analysis $\cdot$ Surrogacy $\cdot$ Species distribution modelling

\section{INTRODUCTION}

The volume of space that can host life on Earth is at least 150 times greater in the oceans than on land (Gjerde 2006). However, scientific knowledge about marine environments is still sparse compared to terrestrial environments due to difficulties to access, observe, and sample most places in the marine realm (Solan et al. 2003, Robinson et al. 2011). The oceans, which cover $70 \%$ of our planet's surface, are esti- 
mated to be $90 \%$ unexplored (Gjerde 2006). Ocean research led by several international initiatives and groups (e.g. Census of Marine Life and the International Council for the Exploration of the Sea [ICES]) has increased significantly over the last decade (Heyman \& Wright 2011, Borja 2014), driven by efforts by many nations to better manage and protect marine resources. In the ocean realm, benthic ecosystems provide important services (Thurber et al. 2013, Galparsoro et al. 2014) but are also increasingly impacted by human activities (e.g. bottom-contact fishing, oil and gas extraction) (Halpern et al. 2008, Williams et al. 2010, Harris 2012). Research on nearbottom environments and their associated biota has become essential to support effective monitoring and management strategies (Thrush \& Dayton 2002, Ramirez-Llodra et al. 2011). Anthropogenic impacts on the seafloor alter benthic biodiversity (Cook et al. 2013, Grabowski et al. 2014), habitats (Jones 1992, Puig et al. 2012), and modify ecosystem structures and functions (Koslow et al. 2000, Olsgard et al. 2008). Ramirez-Llodra et al. (2011) noted that exploration, scientific research, monitoring, and conservation measures are essential to ensure that exploitation of resources does not lead to massive destruction of ecosystems. To protect benthic species from such threats, distribution patterns and ecological dynamics must be better understood (Ramirez-Llodra et al. 2011, Mengerink et al. 2014). Managers need accurate, quantitative and spatially explicit information, at scales relevant to their objectives, in order to support protection and management plans (Anderson et al. 2008, Davies \& Guinotte 2011). Marine habitat mapping has become mandatory in some countries and contexts, such as the 1996 amendment to the United States Magnuson-Stevens Fishery Conservation and Management Act regarding the description and identification of essential fish habitats (Benaka 1999). To ensure that these efforts are as representative as possible, species distributions should be mapped at multiple scales (Lourie \& Vincent 2004, Smith \& Brennan 2012, Shucksmith \& Kelly 2014). Mapping seafloor based on species' habitat requirements is essential and is the first step in implementing scientific management, monitoring environmental change, and assessing the impacts of anthropogenic disturbance on benthic habitats (Roff et al. 2003, Cogan \& Noji 2007, Harris \& Baker 2012a).

Habitats can be defined as physical spaces characterized by a combination of variables of different types in which species can survive (Whittaker et al. 1973). Several definitions of benthic habitats have been proposed. Harris \& Baker (2012a, p. 8) define them as being 'physically distinct areas of seabed that are associated with the occurrence of a particular species'. A more comprehensive definition of benthic habitats could include the chemical environment and water properties known to influence benthic faunal distribution (Kostylev et al. 2001, Cogan \& Noji 2007, Brown et al. 2011a). A benthic habitat can hence be defined as an area of the seabed that is distinct from its surrounding in terms of physical, biological, and chemical variables. Brown et al. (2011a) provide a comprehensive review of types of benthic habitat maps, techniques of data collection, and methods that can be used to create habitat maps. Habitat-based approaches to estimate organism response to landscape heterogeneity have been used for decades in landscape ecology (Turner et al. 2001, Robinson et al. 2011). Because species have a range of environmental preferences and requirements (Hutchinson \& MacArthur 1959), many of these approaches focus on the structure and quantity of potential habitats, either instead of, or in addition to, the distribution of biological populations at the time of sampling.

Habitat maps must be placed in context with the appropriate spatial, temporal, and thematic scales (Cogan \& Noji 2007). Scale is considered to be 'one of the most critical aspects in habitat mapping, as well as one of the most misunderstood' (Greene et al. 2007, p. 145). As Boyce (2006, p. 274) stated: 'Ecologists are still at a fairly naïve pattern-documentation phase in understanding the importance of scale.' Despite the well-known importance of spatial scale in benthic habitat mapping (Brown et al. 2011a), the topic is only briefly mentioned in texts (e.g. Todd \& Greene 2007, Harris \& Baker 2012b) and only a few publications address the implications of scale for benthic habitat mapping. Brown et al. (2011a) includes a complete section on spatial scale in benthic habitat mapping. Other publications have addressed spatial resolution (e.g. Anderson et al. 2008), the impact of scale in management and surrogacy assessment (e.g. McArthur et al. 2009, 2010), and its impact in shallow water monitoring (e.g. Van Rein et al. 2009).

Scale is only briefly acknowledged in the extensive literature on benthic habitat mapping, often with little or no treatment of the role of spatial scale in the production of benthic maps and the interpretation of research results. This lack of treatment likely indicates little awareness and understanding of the importance and role that spatial scale plays in benthic habitat mapping. Fig. 1 illustrates the increase in publications on benthic habitat mapping for the 


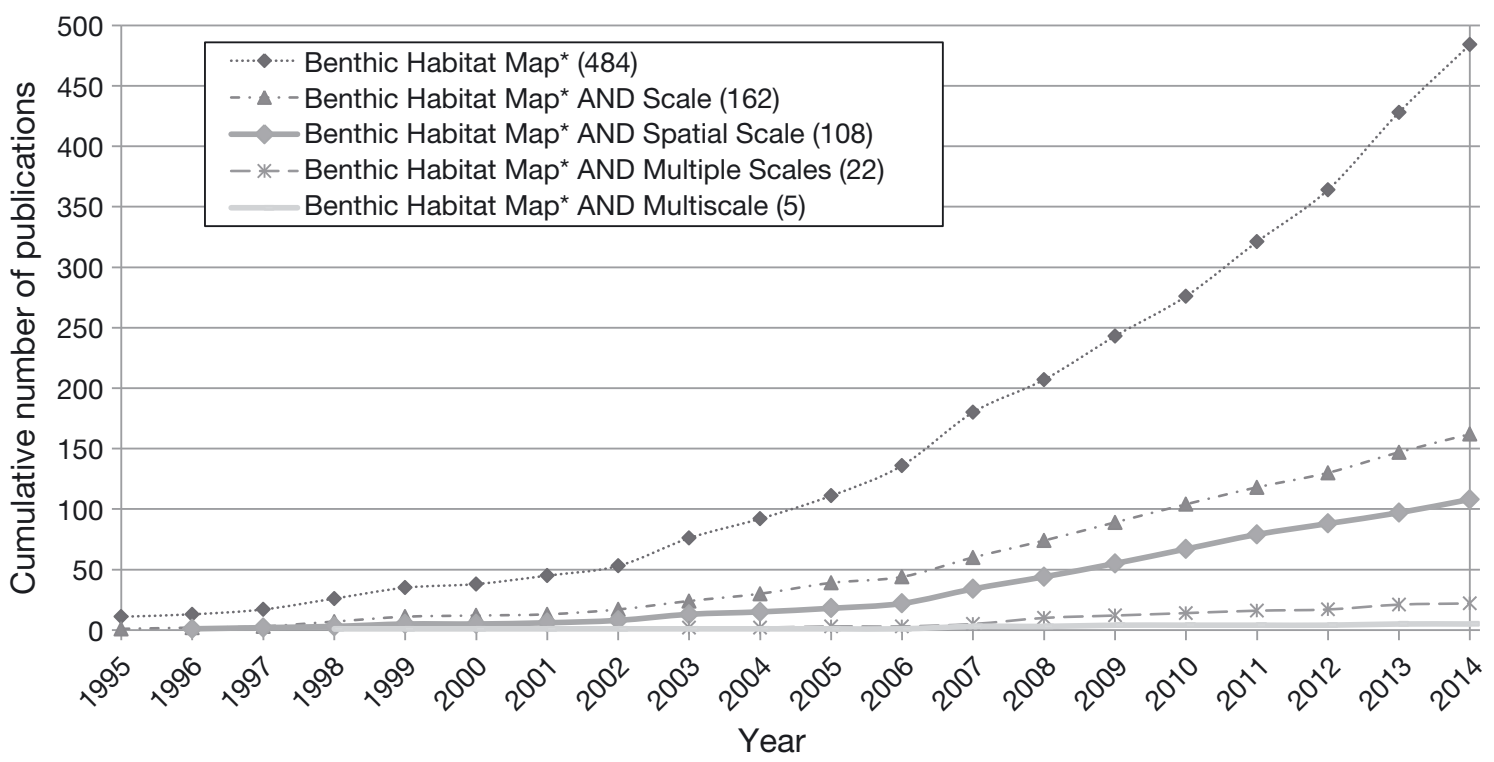

Fig. 1. Cumulative number of publications (articles or reviews) listed in the Scopus database mentioning specific keywords (see key) in their title, abstract or keywords, by the end of 2014

period 1995-2014, and the number of cases that address scale. Approximately a third of the articles and reviews used the term 'scale' in the title, abstract or keywords, with $22 \%$ for 'spatial scale', less than $5 \%$ for 'multiple scales' and 1\% for 'multiscale'; these numbers are much lower than in landscape ecologyrelated publications, where scale is still considered as being insufficiently described (Lechner et al. 2012a).

The aims of this contribution are (1) to review existing knowledge on spatial scale in benthic habitats and their mapping, including the related practices of surrogacy assessment and species distribution modelling, and (2) identify ways to improve benthic habitat mapping practices. The paper is organized as follows. We first review knowledge of scale in ecology, including the difference between scales of phenomenon, observation and analysis. We then introduce the concepts of benthic habitat mapping, including the natural characteristics that can influence marine species distribution, the basis of their representation as spatial data and of their analysis, and the importance of characterizing habitat at multiple scales. Thirdly, we emphasize the need to consider the spatial nature of data in analyzing species' relationships with their environment. Fourth, we discuss current needs and future directions in habitat mapping, and propose a new standard for defining benthic habitat that includes the explicit statement of scale. Finally, we make recommendations regarding the integration of ecological scaling and geographical theories in habitat mapping.

\section{SCALE IN ECOLOGY}

Three types of scale are typically recognized in the ecological literature: spatial, temporal, and thematic. Several definitions of spatial scale have been given depending on the contexts (Schneider 1994, 2001a, Dungan et al. 2002, Lechner et al. 2012b). Spatial scale commonly refers to the spatial characteristic of an object or process, including both its spatial resolution (i.e. level of detail) and geographic extent (Schneider 1994, Gustafson 1998). Like spatial scale, temporal scale is characterized by both resolution (e.g. days vs. minutes) and extent (i.e. range of time) (Schneider 1994). Space and time are intrinsically linked and often depicted in joint space-time diagrams (Stommel 1963, Steele 1978, Delcourt et al. 1983). Thematic scale, also called level of organization, organizational scale, or ecological organization, is linked to the level at which objects of study are described, for instance taxonomic resolution (Levin 1992, Larsen \& Rahbek 2005). Thematic scale is important because the observed relationships of any 2 variables can vary across thematic scales (Pearson 2002, Larsen \& Rahbek 2005, Brown et al. 2011a, 2012). For instance, grouping species with different habitat requirements can result in conclusions that differ from when species are studied individually (e.g. Grober-Dunsmore et al. 2007, Lecours et al. 2013). Understanding the effects of spatial, temporal, and thematic scale is challenging but essential, as many important ecological processes are scaledependent (Turner et al. 2001, Schneider 2009, De 
Knegt et al. 2010). Changes in pattern with changes in scale have been recognized in ecology since the 1950s (Greig-Smith 1952), but the importance of scale only became widely acknowledged in the 1980s (Meentemeyer 1989, Schneider 2001a). Research on scale, on methods to scale-up and scaledown across scales, and on the problem of relating phenomena across scales is fundamental and remains an important focus in many sciences (Wiens 1989, Levin 1992, Schoch \& Dethier 1996). According to Turner et al. (2001, p. 330): 'The effects of scale are now well recognized, but the need for improved quantitative understanding remains critical.'

Lechner et al. $(2012 \mathrm{a}, \mathrm{b})$ distinguish the scale at which a pattern or process occurs from the scale of observation and the scale of analysis. The scale at which a pattern or process occurs is often referred to as intrinsic, operational, or ecological scale. The observational scale relates to the data that are used to describe natural phenomena (e.g. the pixel size, or spatial resolution, on gridded bathymetric data), while the analysis scale relates to the method used to analyze these data (e.g. the size of the analytic window used to perform focal statistics in spatial analysis).

Issues can arise when there is a mismatch between ecological, observational, and analytical scales: appropriate detection of species-habitat relationships and ecological patterns is dependent on the chosen observational and analysis scales (García \& OrtizPulido 2004, Gambi \& Danovaro 2006). For instance, using a $1 \mathrm{~km}$ resolution bathymetric dataset would likely not allow the understanding of how bathymetry relates to species distribution in a coral reef, as knowledge of smaller changes in depth would be required. Observational and analytic scales are often arbitrarily chosen in ecological studies (Levin 1992), due to financial, technical or time constraints (Meentemeyer 1989) and are typically not reported in sufficient details (Pittman \& McAlpine 2003). Wheatley \& Johnson (2009) reviewed the use of multiple scales in terrestrial wildlife-habitat studies, finding that $70 \%$ of the articles used arbitrarily chosen scales, with no consideration of the scales relevant to wildlife or to environmental variables. They mentioned that when such choices are made, 'published results may reflect scale artefacts' and scale-dependent processes may be missed 'by examining irrelevant or redundant scales of observation' (Wheatley \& Johnson 2009, p. 151). Scale artefacts are observations that seem to explain the studied pattern or process, but may not be causally linked or cannot be validated due to the choice of observational scale (Wheatley \& Johnson
2009, Lechner et al. 2012b). In order to avoid scale artefacts and missing important patterns or processes, data and analysis need to capture the essential elements of the habitat, meaning that the observational and analytic scales should encompass the ecological scales of the biological or environmental phenomenon being studied (Hobbs 2003, Mayor et al. 2009, Goodchild 2011). Habitat structure must then be measured at spatial scales relevant to the organism of interest (Pearson 2002, Gallucci et al. 2009, De Knegt et al. 2010). For instance, the habitat of a wideranging shark would not be measured at the same scales as the habitat of a small cavity-dwelling reef fish, even if they are found within the same geographic area.

No single scale, be it spatial, temporal or thematic, is appropriate for the study of all ecological problems, and all scales do not have similar explanatory powers (Clark 1985, Wiens 1989, Levin 1992, Willis \& Whittaker 2002). For instance, coarse-scale data can help understand regional patterns of terrestrial and marine species biogeography (e.g. Rahbek \& Graves 2001, Davies et al. 2008) but may be insufficient for identifying specific conservation areas (Davies \& Guinotte 2011). Models created with coarse-scale data to predict a species' geographic distribution can be improved using better knowledge of its habitat requirements gained from finer-scale information (Bryan \& Metaxas 2007, Etnoyer \& Morgan 2007, Davies \& Guinotte 2011, Ross \& Howell 2013). However, saying that no single scale is appropriate does not mean that all scales serve a purpose equally well or that scaling laws or patterns cannot be defined (Levin 1992).

Spatial scale is an important consideration when studying organism and habitat structure interactions (McCoy et al. 1991, Pearson 2002). Habitat selection by a particular species can occur and be measured at some scales and not necessarily at others (Owen 1972, Boyce 2006). For instance, Anderson et al. (2005) found that elks select their habitat based on broad-scale spatial distribution of wolves in conjunction with fine-scale selection of forage areas. In a marine context, the associations of infaunal (De Leo et al. 2014), sessile (Schneider et al. 1987), and mobile epibenthic species (Grober-Dunsmore et al. 2007, Kendall et al. 2011) with their environment were all found to vary with spatial scale. The concept of habitat is both scale-dependent (Pearson 2002) and species-specific (Pandit et al. 2009). For instance, habitat specialists, such as coral reef gobies (Munday et al. 1997), live in a very specific habitat characterized by a narrow range of environmental conditions 
and respond to more fine-scale processes. On the other hand, habitat generalists, such as the copepod Nitocra spinipes (Pandit et al. 2009), can tolerate a broad range of environmental conditions and respond to more broad-scale processes. More generally, Schneider et al. (1987) found that mobile species often show decoupling from the environment at finer scales, and habitat association at coarser scales, compared to finer-scale coupling with habitat by sessile species. Meyer \& Thuiller (2006) reported that the majority of species respond to habitat characteristics at more than one scale at the same time. Despite that, a response measured at one particular scale cannot always be used to predict habitat use at another scale (VanderWerf 1993, Apps et al. 2001).

\section{SCALE IN BENTHIC HABITAT MAPPING}

\section{Review of concepts and methods}

Habitat mapping

The complex interactions between biological, physical, chemical, and behavioural elements of the marine environment can make benthic habitats difficult to map (Zajac 2008, Rigby et al. 2010). The integration of data representing these elements at multiple scales is especially challenging (Brown et al. 2011a). Traditional data-acquisition techniques can be limited by varying factors, including depth (as with optical remote sensing that only captures data in shallow waters), visibility (as with cameras), and time (as with SCUBA diving) (Dunn \& Halpin 2009, Costa et al. 2014). Whilst some techniques can help delineate benthic habitats at some specific scales, they present challenges when trying to delineate benthic habitats at other scales. For instance, seafloor acoustic mapping from the surface and sparse ground-truthing in deeper waters provide information at a scale that Davies et al. (2008) considered regional, but lack the capacity to characterize finer-scale patterns and processes (Stone 2006, Davies et al. 2008, Tittensor et al. 2009). On the other hand, SCUBA diving allows the collection of fine-scale data in shallow waters but cannot generate a broader characterization of ecosystem pattern (Costa et al. 2014). The use of bathymetric LiDAR (in shallow waters) and acoustic remote sensing (in deeper waters) can help reduce these sampling gaps, by providing continuous and high-resolution data necessary for mapping over greater areas, and thus at scales that may be more relevant for understanding pattern and process in these habitats (Kenny et al. 2003). Despite their strengths, these techniques have their own limitations, as they do not necessarily provide data of sufficient resolution to understand very fine ecological processes. However, combining acoustic or LiDAR data with in situ observations, high-resolution geoscientific and environmental information, and spatial analytical techniques does allow for more accurate quantitative characterization of habitat at multiple scales, in addition to providing a framework for mapping the distribution of benthic species and interpreting spatial patterns in biodiversity (Whitmire et al. 2007, Wedding et al. 2008, Brown et al. 2011a, Harris \& Baker 2012a).

Brown et al. (2011a) identified 3 of the most common approaches to benthic habitat mapping: abiotic surrogate mapping that does not consider biological data, and unsupervised (top-down approach) and supervised (bottom-up approach) classifications that integrate biological data in different ways (see Fig. 4 in Brown et al. 2011a). These methods correspond to what the 'Review of Standards and Protocols for Seabed Habitat Mapping' published by MESH (Mapping European Seabed Habitats) identified as the general approach to benthic habitat mapping: the spatial integration of different datasets, usually within a geospatial environment (Coggan et al. 2007). While a number of studies (e.g. Brock et al. 2004, Wedding \& Friedlander 2008) mapped benthic habitats in shallow environments using bathymetric LiDAR, optical remote sensing, or SCUBA diving, this approach often focuses on the use of acoustic remote sensing (e.g. multibeam echosounders, sidescan sonars) to collect spatial information on the characteristics of the seafloor (Brown et al. 2011a); most of the 57 case studies presented in Harris \& Baker (2012b) used either backscatter or bathymetric data, or both. For example, Copeland et al. (2012) combined information extracted from bathymetric and backscatter data with biota in a sub-Arctic fjord to determine 6 types of benthic habitats and to identify patterns of biodiversity. All the techniques used to map both shallow and deeper waters influence or determine the scale of data collection and analysis. For instance, the spatial resolution and extent of acoustic bathymetric data depends on the sensor-toseafloor distance (e.g. Lecours \& Devillers 2015) and the systems used (Kenny et al. 2003): the shorter the distance, the higher the resolution and the lower the extent.

In parallel, approaches from terrestrial ecology are increasingly used in marine ecology to represent environmental heterogeneity as habitat maps. Sea- 
scape ecology draws on techniques from landscape ecology, using spatial pattern metrics to quantify the seascape structure and delineate patch-based models of habitat type (see Boström et al. 2011, Pittman et al. 2011, Wedding et al. 2011). The size of habitat patches can be an indicator of the spatial scale at which species use an environment when linked to species distribution and behaviour (Pittman \& McAlpine 2003, Pittman et al. 2007). For instance, Hitt et al. (2011) tracked fish movements, linking them to seascape structures to study habitat use in relation to patch types and connectivity, which allowed quantifying the extent of the environment that the fish were using. The literature on seascape ecology is however still scarce (Pittman et al. 2011). Applications are mostly in coastal shallow environments, using optical remote sensing (i.e. aerial photography or satellite remote sensing) (e.g. Kendall \& Miller 2010) or bathymetric LiDAR data (e.g. Purkis \& Kohler 2008), and are often applied to reef fishes (e.g. Kendall et al. 2011). Despite its potential to explain marine ecological patterns and processes at multiple scales (Schoch \& Dethier 1996), seascape ecology has yet to be implemented in deeper water using acoustic bathymetric data. Habitat maps developed in a seascape ecology context also involve the consideration of spatial scale, as the spatial pattern metrics are dependent on the resolution and extent of the input data that influence the minimum mapping unit (MMU) (Saura 2002, Fassnacht et al. 2006, Kendall et al. 2011). MMU is the size of the smallest area to be mapped as a discrete unit, and its selection determines the scale at which patches are defined in a seascape: as the MMU increases, rare and smaller features tend to not be considered by the analysis, which can lead to erroneous interpretation (see Kendall \& Miller 2008).

Significant progress has been made in the understanding of benthic habitats in the last decade (see Todd \& Greene 2007, Harris \& Baker 2012b) despite the difficulties associated with their mapping, modelling, and management (Diaz et al. 2004). Much work remains to be done to gain an adequate understanding of these complex ecosystems at relevant scales. For instance, very little work has been done on infaunal benthos (see De Leo et al. 2014). Not only is most benthic diversity infaunal, but the rate of release of nutrients into the water column, a key benthic variable, is driven mostly by infaunal activity. Mapping benthic diversity to the species level is not possible in the absence of continuously mappable surrogates (see next subsection) for any one species. However, with sufficiently fine-scale data, it would be possible to map evidence of biogenic flux, such as castings or burrow diameters, through the sediment surface. For instance, acoustic reflectivity (backscatter) can capture fine-scale information of the sediment surface, which can then be combined with in situ groundtruthing in a benthic modelling approach (e.g. Brown et al. 2011b, Freitas et al. 2011, Copeland et al. 2012). Another issue that constrains complete understanding of benthic ecosystems is the species-specific relation to habitat as a function of scale, which in turn complicates the study of species assemblages (Grober-Dunsmore et al. 2007, Howell et al. 2010, 2011; see also Brennan et al. 2002, Brown et al. 2011a). For example, Schneider et al. (1987) found that the scale-dependent association between population density and substrate differed between mobile and sedentary fauna.

\section{Surrogacy}

As in terrestrial ecology, the challenges associated with sampling marine organisms in relation to their environment has led to an increasing use of surrogates, also known as 'proxies' (McArthur et al. 2009, 2010, Anderson et al. 2011). A surrogate can be defined as 'a measurable entity that will represent, or substitute for, a more complex element of biodiversity that is more difficult to define or measure' (Harris \& Baker 2012b, p. 899). Surrogates can be any measurable characteristic of the environment, sampled either in situ at specific locations (e.g. sediment pH), or provided as continuous or near-continuous coverage, such as bathymetry derivatives (e.g. seabed roughness or slope). Before mapping habitats, surrogate variables for a particular species first need to be identified, together with the strength of covariation in the study, and the establishment of a biological basis for the covariation. For instance, the selection of surrogates to be tested and the scale at which they should be tested may be based on knowledge gained from previous observations, experimental work or some evidence of causal connection (Brennan et al. 2002). Surrogates may be relevant only at particular scales (Urban et al. 1987, Gambi \& Danovaro 2006). For instance, Tong et al. (2013) found aspect (the geographic orientation of the slope) to be a good surrogate of the cold-water coral Paragorgia arborea's presence over areas of $30 \times 30 \mathrm{~m}$ and $90 \times 90 \mathrm{~m}$, but not at a broader scale. They linked this result to the presence of finer-scale bottom currents in the study area that bring food to the corals, which is not the case for broader-scale currents (Tong et al. 2013). 
Once defined, surrogates can be used to map habitats, predict or estimate species distribution, and build habitat suitability models (e.g. Lucieer et al. 2013, Hill et al. 2014). The use of surrogates for these purposes cannot be trusted at spatial scales other than the scale at which the surrogate was defined.

\section{Species distribution modelling}

Combining georeferenced species occurrence data with environmental variables to develop habitat suitability and predictive distribution models is an important approach increasingly used in the marine environment (Heyman \& Wright 2011, Robinson et al. 2011, Brown et al. 2012, Hill et al. 2014, Vierod et al. 2014), especially for protection and management purposes (Ross \& Howell 2013). These models build on existing knowledge of species-environment relationships, either directly or via surrogates, to predict the location and extent of potential habitat in areas where only environmental information is available (see Elith \& Leathwick 2009, Zimmermann et al. 2010 for general reviews; and Robinson et al. 2011, Vierod et al. 2014 for specific reviews for the marine environment). The criteria (Brennan et al. 2002, Franklin 2009) to consider in the selection of a model for a particular application are (1) species characteristics, (2) data availability, (3) the observational and analysis scales, (4) stability in time (e.g. bathymetry compared to temperature), and (5) the biological and physical underpinnings (if any) of the model. As in terrestrial ecology, few marine studies address the issues of choosing an appropriate range of spatial scales at which to identify surrogates of species habitat or identify the appropriate scales at which to develop predictive models (Franklin 2009). A coarser scale model may underrepresent the area of suitable habitat since the finer-scale habitat features that drive species distribution are not captured by the data (Seo et al. 2009, Vierod et al. 2014) (see also Fig. 2). The scale (extent) of the study area also has a direct impact on the quality of the models (VanDerWal et al. 2009, Hijmans 2012), and Meyer \& Thuiller's (2006) meta-analysis of species distribution modelling studies found that the use of environmental variables at more than one scale tends to give more accurate predictions. In the deep sea, the implementation of effective habitat suitability models is limited by the resolution and extent of environmental data (Vierod et al. 2014), and will only be possible if high-resolution data become globally available (Davies et al. 2008). Some data may not be available for an area, or may be available at an inappropriate scale. Often, certain variables (e.g. temperature, bottom current speed) are only available at a coarser resolution than other variables (e.g. slope and rugosity, measured using acoustic remote sensing techniques). Downscaling or improved spatial measurement of the former to a level in line with the latter is needed to free models from errors in cross-scaling and to put knowledge of species distribution relative to habitat on a sound basis.

\section{Ecological scale: benthic species and their environment}

\section{Environmental and biological surrogates}

Several environmental variables were found useful in characterizing marine habitats, with differing degrees of importance depending on species (e.g. Freeman \& Rogers 2003), locations (e.g. Georgian et al. 2014), settings (e.g. submarine canyons) (e.g. De Leo et al. 2014), and spatial scales (e.g. Gambi \& Danovaro 2006, Henry et al. 2013). This diversity in use of environmental variables highlights the difficulties in quantifying the distribution of benthic organisms in relation to habitat. Reviews of potential surrogates of marine benthic biodiversity can be found (e.g. McArthur et al. 2009, Howell 2010, Harris $\&$ Baker 2012b) but only McArthur et al. (2010) discuss the usefulness of surrogates in relation to spatial scale.

In addition to physical and chemical factors, biological factors and ecological interactions likely explain the distribution of benthic organisms at different scales (Robinson et al. 2011). For example, reproduction strategies can influence species distribution, following spatial patterns in which organisms expect to disperse gametes over greater areas to reduce aggregation (Gage \& Tyler 1999). Ecological interactions can also be used as surrogates; if predation or commensalism is observed between 2 species (e.g. between structure-forming species and fishes), the presence of one could predict the other (Ward et al. 1999, Tissot et al. 2006, Mumby et al. 2008, Baillon et al. 2012). Both intraspecific and interspecific interactions vary with scale on land (Wiens et al. 1986b, Sherry \& Holmes 1988) and in the ocean (Haury et al. 1978). Mellin et al.'s (2011) meta-analysis of the effectiveness of biological surrogates in marine studies showed that biological surrogates tend to be more effective at finer spatial scales (i.e. smaller spatial extent). According to Leaper et al. (2012, p. 858), 'the 
need for effective biological surrogates is especially critical in the marine realm, where a large number of species remain undescribed'. Yet biological surrogates are rarely used in habitat mapping as they are difficult to assess at meaningful (often fine) spatial scales (Muotka et al. 1998, Mellin et al. 2011, Snickars et al. 2014). The addition of biological surrogates to species distribution models can potentially improve predictions (Austin 2002, Robinson et al. 2011).

\section{Combined environmental influence and multicollinearity}

Environmental variables identified as surrogates can act together to influence species distribution. For instance, the combination of topography and currents influences the levels of connectivity among populations for reproduction at different scales (Adams \& Flieri 2010, Rex \& Etter 2010). On seamounts, millimetre-scale colonization patterns are affected by coarser-scale flow patterns, however the motion of the fine-scale benthic boundary layer is also a determining factor (Gage \& Tyler 1999, Young 2009). On continental slopes, rough seafloors interact with meso-scale currents to create complex circulation patterns that could potentially lead to the isolation of populations (Rex \& Etter 2010). Such relationships complicate data analysis because multicollinearity among variables occurs within and across scales (Rengstorf et al. 2012, Laffan et al. 2014). Multicollinearity occurs when 2 or more explanatory variables (e.g. water depth and temperature) are highly correlated (see Tabachnick \& Fidell 2013), obscuring the influence of each variable (Hengl \& MacMillan 2009, Tabachnick \& Fidell 2013). Multicollinear explanatory variables are common in marine ecology but rarely considered in analyses (Wedding et al. 2011): multicollinearity should systematically be tested (Pittman et al. 2009). Statistical methods to address the problem can be found in Dormann et al. (2013) and Tabachnick \& Fidell (2013).

That explanatory variables covary raises a question: how many and which variables are necessary to best characterize a habitat? In the past, a single surrogate was often used, but it is now widely accepted that biogeographic patterns are best explained by a combination of multiple variables (Hagberg et al. 2003, McArthur et al. 2009). Too few covariates can result in an overly general habitat characterization (Barry \& Elith 2006, VanDerWal et al. 2009). The opposite, too many variables, can result in model over- fitting (Peterson \& Nakazawa 2008). According to Peterson et al. (2011), the number of variables will depend on the studied species, the complexity of the habitat, the availability of data, and the observational and analysis scales. Mateo Sánchez et al. (2014) argue that it is as important to identify the relevant environmental factors as to identify the scales at which these drive species distributions. Selecting relevant variables and at relevant scales is essential to the quality of habitat maps and the performance of predictive models (Austin 2002, Williams et al. 2012). The choices of variables and observational and analysis scales need to be based on their ecological relevance as these choices can impact the measurements of relationships between fauna and environmental variables (Araújo \& Guisan 2006, Synes \& Osborne 2011). Austin \& Van Niel (2011) however report that assumptions made in the literature about the ecological relevance of variables vary among publications, are sometimes inconsistent, and so need to be revisited with a consideration of spatial scale.

\section{Observational scale: representing nature with spatial data}

\section{Adequacy of spatial data}

When expressed as ecogeographical data (i.e. ecological variables with a geographic component), surrogates have a spatial dimension defined by their latitude, longitude, and depth (or altitude for terrestrial applications). A measure derived from these 3 spatial variables is geographical distance, an important predictor of fish species distributions in coral reefs (Pittman \& Brown 2011) and hard-bottom habitats (Dunn \& Halpin 2009). These spatial variables define the spatial scale (resolution and extent) of ecogeographical data and can themselves be used as surrogates (McArthur et al. 2009). For instance, small changes in depth can better explain changes in populations than larger changes in latitude and longitude (Rex \& Etter 2010). However, their ecological meaning is arguable (Pittman \& Brown 2011). Depth for instance may itself be a surrogate of a causal variable such as light or temperature. A strong relation between a biological variable and non-causal surrogate (e.g. depth) can therefore obscure the relation to an underlying causal variable (e.g. light or temperature), reducing the predictive power of important covarying environmental variables (e.g. Araújo \& Williams 2000, Clarke \& Lidgard 2000, Hothorn et al. 2011). 


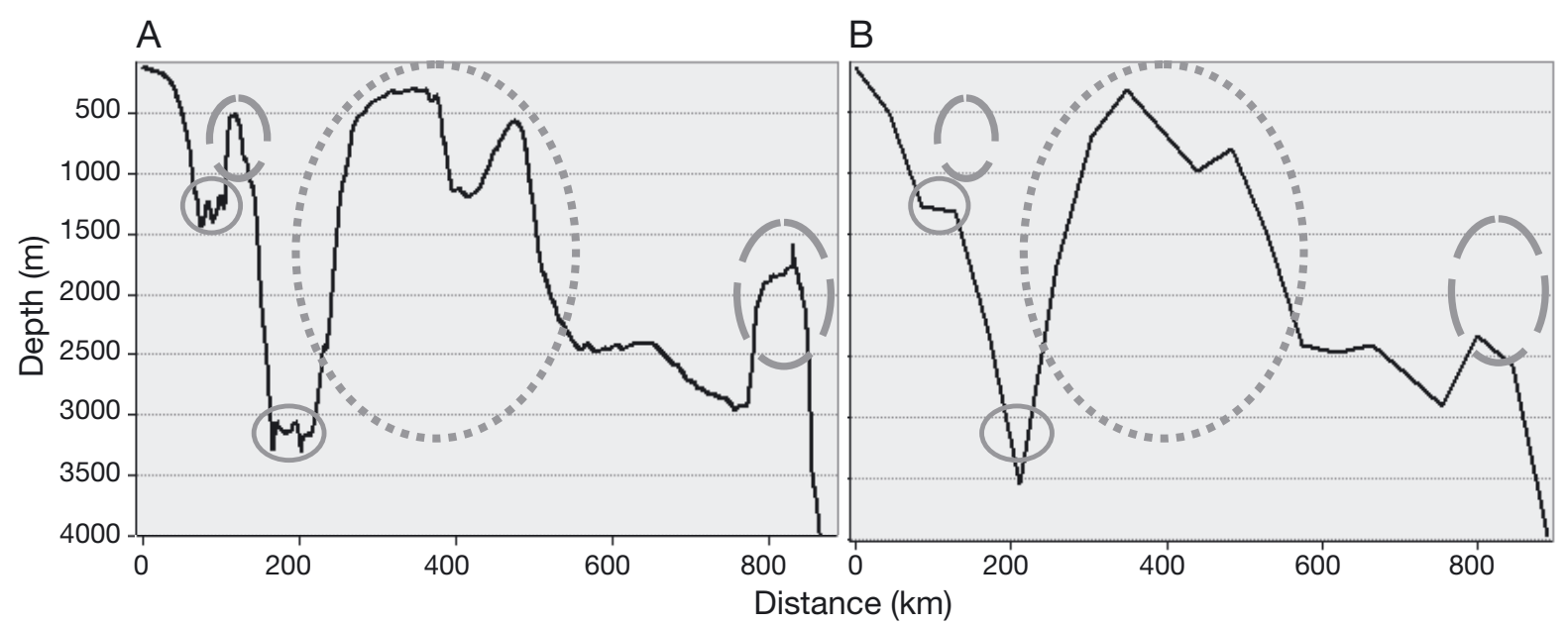

Fig. 2. Seabed profiles (black lines) showing fine-scale (solid gray ellipses), intermediate-scale (dashed gray ellipses) and broad-scale (dotted gray ellipses) topographic features delineated using (A) finer-scale and (B) coarser-scale bathymetric data. By using only a coarse observational scale, information on potentially ecologically important finer-scale features is not captured. (Conceptual figure shows bathymetric profiles derived from the General Bathymetric Chart of the Oceans [GEBCO] dataset; www.gebco.net/)

All data are not equally good at capturing the relevant information. Fig. 2 illustrates this idea with the example of bathymetry: if one finds that only broadscale bathymetric features, such as a large seamount (dotted ellipses), drive species distribution, then finer-scale data are not needed. On the other hand, if intermediate-scale features (e.g. smaller pinnacles or banks; dashed ellipses in Fig. 2) influence species biogeography, finer-scale data would be required. If the detailed topography (e.g. single boulder; solid ellipses in Fig. 2) represent ecologically important habitats, even finer-scale data would then be essential to capture the important information.

The role of spatial scale has never been formally assessed in marine habitat mapping, despite repeated calls for an improved scientific understanding of benthic habitats at finer scales to allow better prediction of the geographic distribution of benthic species (Etnoyer \& Morgan 2007, Davies et al. 2008, Davies \& Guinotte 2011, Rengstorf et al. 2013). This lack of assessment makes it difficult to define which observational scales are 'fine enough' and which ones represent the upper limit of usefulness (Wilson et al. 2007). In terrestrial environments, local biological interactions often complicate the observation of the relationships between species and abiotic variables; the opposite occurs at coarser scales (Levin 1989, Sarkar et al. 2005), which makes fine-scale studies more appropriate to investigate details of biological mechanisms and broad-scale studies for generalizations (Wiens 1989). Wiens (1989) suggested that these patterns were likely to be the same in the marine realm but Steele (1991) showed that biologi- cal and physical phenomena do not scale in the same way in the ocean as on land. Planktonic life stages, the ability of some pelagic larvae to remain in an undeveloped stage until they find a suitable location to settle, and ocean fluid dynamics allow broad-scale dispersal into fine-scale suitable environments, which is not comparable to the finer-scale dispersal of many terrestrial species (Gray 1966, Carr et al. 2003, Kinlan \& Gaines 2003). In benthic habitat mapping, it is possible that an intermediate observational scale finer than the current coarse-scale studies (although not too fine) could provide more useful information (cf. dashed ellipses in Fig. 2). For instance, Roberts et al. (2008) investigated communities at a local scale and concluded that intermediatescale mapping might be useful to improve their results.

\section{Data quality and spatial scale}

Several factors, including multicollinearity, autocorrelation (see 'Adding geographic context: Spatial autocorrelation'), and spatial and thematic scales, can influence the accuracy of habitat maps (see Fig. 4 in Wedding et al. 2011). Despite recommendations to investigate and map variable uncertainty and error propagation when mapping habitats and species distribution (Rocchini et al. 2011, Beale \& Lennon 2012, Vierod et al. 2014), uncertainty and quality issues associated with spatial and non-spatial data are rarely addressed in habitat mapping (Lechner et al. 2012a). Spatial data quality directly impacts the reliability of habitat maps, predictive models, and sta- 
tistical description of species-habitat relationships (Menke et al. 2009, Moudrý \& Šímová 2012). Data quality is conceptually related to spatial scale (Zhang et al. 2014, Lecours \& Devillers 2015, Pogson \& Smith 2015). For instance, the finer the data resolution, the more that uncertainty and poor positional accuracy influence relationships between variables (Hanberry 2013). Spatial matching between ecogeographical variables is particularly important: the positional error on biological data should always be smaller than the spatial resolution of the environmental data (Moudrý \& Šímová 2012, Lecours \& Devillers 2015) to avoid the emergence of false relationships between species and the environment, or the overestimation of a variable's range of values associated with a species (Guisan \& Thuiller 2005, Guisan et al. 2007).

In habitat mapping and predictive modelling, a trade-off between data quality (i.e. accuracy and precision), sample size, and spatial scale (i.e. resolution and extent) must be considered (Brennan et al. 2002, Lecours \& Devillers 2015). Despite attempts to address this challenge (e.g. Braunisch \& Suchant 2010), it is still unclear which characteristics should be given a higher priority in sampling strategy. Fine resolution data arguably yields better predictive models if the data quality is adequate, even if the sample size of biological data is smaller (Huston 2002, Engler et al. 2004, Kaliontzopoulou et al. 2008, Reside et al. 2011, Williams et al. 2012), but this conclusion is not unanimous (Braunisch \& Suchant 2010). Some authors suggest using uncertainty to weight the variables in modelling and statistical analyses; information with less positional error can increase precision and thus improve models (Beale \& Lennon 2012, Moudrý \& Šímová 2012).

\section{Analysis scale: influence on analyzing ecogeographical data}

Statistical relationships depend on the scale of analysis and results can vary as a function of it (Greig-Smith 1952, Rahbek \& Graves 2001, Dungan et al. 2002). An example is given in this sub-section using surrogate variables derived from bathymetry, which are among the most sensitive to the scale of analysis. Bathymetric data have proven their potential to advance understanding of seafloor ecosystems and their value for habitat mapping (Anderson et al. 2008, Brown et al. 2011a), and can be used in geomorphometry (i.e. terrain analysis) to quantify seafloor topography and complexity (Lecours et al. 2015). In the last decade, a range of terrain attributes (e.g. slope, curvature) were found to have a relationship to marine biodiversity (McArthur et al. 2009), thus inducing an increase in the application of geomorphometric techniques in marine habitat mapping (e.g. Wedding et al. 2008, Zieger et al. 2009, Rengstorf et al. 2012, Tong et al. 2013, Dolan \& Lucieer 2014). The relationship between spatial scale and terrain attributes has become an important research focus in geomorphometry (e.g. Florinsky \& Kuryakova 2000, Schmidt \& Andrew 2005, Deng et al. 2007, Li 2008), but a good understanding of scaling methods is still missing from geomorphometric analysis (Drăgut et al. 2009). Terrain attributes vary with scale (Evans 1972) and so their computation does not result in only one true, real fixed value, but in a range of possible values that depend on the resolution of the data and the extent of the analysis window (Shary et al. 2002, Hengl 2006). In the marine environment, coarse-scale geomorphometric analyses may not be adequate to resolve smaller features important for benthic biodiversity (Rengstorf et al. 2012, Lecours et al. 2013). The effects of the spatial resolution of bathymetry and terrain attributes on habitat suitability models are discussed in more detail by Rengstorf et al. (2012). Issues related to scale in geomorphometric analysis are similar to those in ecology and habitat mapping: it is widely accepted that a single scale (fixed resolution and window size) cannot completely describe a surface and capture all features of interest in an area (cf. Fig. 2) (MacMillan \& Shary 2009, Goodchild 2011). Yet many applications use a single scale, with an arbitrary choice of spatial resolution for the input surface and a single neighbourhood size (MacMillan \& Shary 2009). This limits analysis to those features that are observable at a single scale, which can have a significant impact on habitat maps and consequently on the resulting conclusions on species-habitat relationships. Similar scaling issues arise in the analysis of environmental data other than bathymetry.

\section{Multiscale and multi-design approaches}

$$
\text { Multiple scales and the MAUP }
$$

It has long been argued that ecology and geography would benefit from the adoption of a multiscale perspective in research, applications, and management (e.g. Stone 1972, Legendre \& Demers 1984, Wiens et al. 1986a, Addicott et al. 1987, Meentemeyer 1989, Conroy \& Noon 1996, Brennan et al. 2002, Pittman \& McAlpine 2003). According to Wiens 
(1989, p. 394), 'studies conducted at several scales or in which grain and extent are systematically varied independently of one another will provide a better resolution of domains, of patterns and their determinants, and of the interrelationships among scales.' The implementation of multiscale analysis is, however, challenging and thus remains sporadic (Wheatley \& Johnson 2009) due to various difficulties including objective choice of sampling scales, simultaneous sampling of multiple scales (Addicott et al. 1987, Brennan et al. 2002), and the modifiable areal unit problem (MAUP) (Gehlke \& Biehl 1934, Openshaw 1984, Marceau 1999), also known as change-ofsupport (COS) in spatial statistics (Cressie 1993, Cressie \& Wikle 2011). MAUP is defined by Harvey (2008, p. 284) as 'the assumption that a relationship observed at one level of aggregation holds at another' and by Heywood et al. (2006, p. 416) as a 'problem arising from the imposition of artificial units of spatial reporting on continuous geographic phenomena resulting in the generation of artificial spatial patterns.' Combining data from 2 observational scales (e.g. when developing a habitat map) is invalid due to MAUP, and results from 2 different analytic scales (e.g. results of the quantification of specieshabitat relationships at different scales) are not comparable: the aggregation of information taking place across changing spatial resolution or extent modifies the statistical properties (e.g. means, variances, and covariances) of the data, possibly resulting in distorted relationships between variables. Thematic scales can be very sensitive to MAUP. MAUP is related to Goodchild's (2011) concept of cross-scale inference, which occurs when inferences made at a coarser scale are transferred to a finer scale. Cross-scale inference is directly related to the concepts of ecological and atomistic fallacies (Robinson 1950, Cressie \& Wikle 2011, see Lloyd 2014). The action of inferring across scales without checking for MAUP or cross-scale inference may lead to misinterpretation of results (Openshaw \& Taylor 1979, Meentemeyer 1989) and unfounded conclusions. However, methods exist to deal with MAUP: Zhang et al. (2014, p. 147) elaborate on multivariate geostatistics 'to facilitate multisource and multiscale data integration', a relevant method for habitat mapping where data are often collected at different scales and with different sensors.

\section{Multiscale and multi-design frameworks}

Wheatley \& Johnson (2009) distinguish multiscale from multi-design sampling. The former is characterized by 2 elements: (1) the same environmental variables must be analyzed across scales and (2) there needs to be a change in only one of the 2 elements of spatial scale (i.e. resolution or extent). When both the spatial extent and resolution are changed, a study is multi-designed rather than multiscale (see Fig. 2 in Wheatley \& Johnson 2009). Fig. 3 illustrates the difference between the 2 approaches. In a number of studies, the term 'multiscale' is inappropriately used to characterize the independent use of multiple scales, thus corresponding to a 'multi-design' approach (e.g. Brennan et al. 2002, Anderson \& Yoklavich 2007, Georgian et al. 2014). The distinction is important as multi-designed studies cannot allow

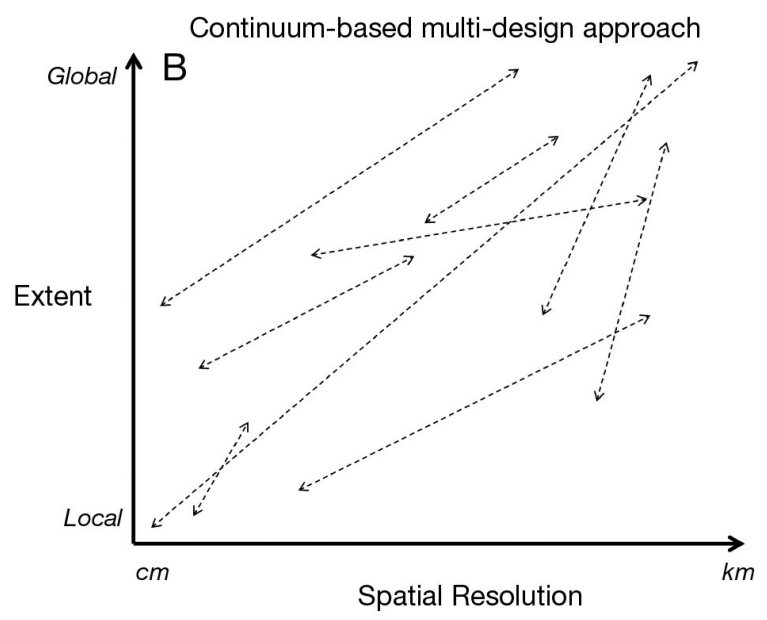

Fig. 3. (A) Multiscale and (B) multi-design continuum-based approaches. Both extent and resolution vary in a multi-design approach, while only one of these 2 scale characteristics is modified in a multiscale survey; each dotted line illustrates an example of how a single study could be framed 
generalization and comparison of results between the different scales due to MAUP (Jelinski \& Wu 1996, Wu et al. 1997, Nelson 2001; see Lechner et al. $2012 \mathrm{~b}$ for MAUP in multiscale studies). Despite potential errors of interpretation caused by MAUP, comparisons between scales are often performed in the literature without exploring its effects.

Studying benthic habitats at multiple scales

Benthic habitat studies at multiple scales were first performed along transects (e.g. Schneider et al. 1987, Schneider \& Haedrich 1991). Extending knowledge gained from this type of study to 2-dimensional mapping is challenging in terms of logistics, data volume, and analytic complexity. Recent work has begun to meet these challenges by looking at the differences between local and regional settings, and showing the importance of observing and mapping seafloor habitats at more than one scale (Wilson et al. 2007, Davies et al. 2008, Wedding et al. 2008, Zieger et al. 2009, Tong et al. 2013). In species distribution modelling, combining data from different scales has improved model reliability and performance (Wu \& Smeins 2000, Store \& Jokimäki 2003, Mateo Sánchez et al. 2014).

Benthic habitat studies at multiple spatial scales have generated several insights. For instance, some variables (substrates, food supply) were found to best explain species distribution at relatively fine scales (Davies \& Guinotte 2011, Edinger et al. 2011). Conversely, other variables (e.g. productivity) were found to have a stronger influence at relatively coarse scales (Davies et al. 2008). Still other variables (e.g. depth) were found to be important at both finer and coarser scales. However, these conclusions are constrained by the observational and analysis scales used in these studies, which did not cover a broad continuum of spatial scales. For instance, fine-scale ocean chemistry could also be found to be locally important if studied within an appropriate range of fine scales.

\section{ADDING GEOGRAPHIC CONTEXT BY CONSIDERING THE SPATIAL NATURE OF DATA}

When mapping habitats, it is important to consider the spatial attributes of measurements. Beyond the questions of spatial scale, considering spatial properties of the data is vital in understanding ecological complexity in benthic habitats (Brown et al. 2011a) and in supporting management decisions about these habitats (Katsanevakis et al. 2011, Galparsoro et al. 2014). Spatial heterogeneity (spatial nonstationarity) and spatial autocorrelation (spatial dependence) are properties of most ecogeographical data: spatial heterogeneity refers to the level of variation of a property across space, i.e. if an observed variable varies locally or globally (Miller 2012), while spatial autocorrelation (SAC) is 'the correlation of a variable with itself' (Lloyd 2014, p. 13) and quantifies the observation that spatially closer objects tend to be more similar than spatially distant objects (Tobler 1970). These 2 properties can strongly affect observed relationships and predictive models (Foody 2004, Hothorn et al. 2011, Hijmans 2012). Finley (2011) compared predictive statistical models that account for spatial heterogeneity and SAC to regular regression models. This comparison showed that models accounting for both properties performed better than non-spatial models or models accounting for SAC alone. Spatial heterogeneity and SAC are also strongly scale-dependent, varying with both resolution and extent (Meentemeyer 1989, Legendre 1993, Dutilleul \& Legendre 1993, Lloyd 2014). Zhang et al. $(2014$, p. 67) stated that 'the interactions between spatial dependence and spatial heterogeneity have been shown previously to alter local definitions of scales.' Consequently, standard statistics based on the assumptions of independent and identically distributed (IID) variables, while used in many ecological studies, should not be used if they violate these statistical assumptions (Meentemeyer \& Box 1987, Marceau \& Hay 1999, Brennan et al. 2002, Goodchild 2004, Beale et al. 2010, Windle et al. 2010). Demšar et al. (2013) identify the need to promote 'spatially aware' statistical methods, and other authors advocate for 'the need to move beyond potentially misleading global regression models which can obscure the space-varying nature of relationships between the outcome variable of interest and covariates' (Finley 2011, p. 149, based on Foody 2004). Nevertheless, standard IID statistics are still often used (Austin 2002, Brennan et al. 2002, Fortin et al. 2005).

\section{Spatial autocorrelation}

While rarely considered in marine habitat mapping studies, SAC is a well-known scale-dependent phenomenon in geography and ecology (Legendre \& Fortin 1989, Legendre 1993) that should always be assessed before conducting spatial analysis (Dormann et al. 2007, Moudrý \& Šímová 2012, Laffan et al. 2014, 
Vierod et al. 2014). SAC can be present even when samples are collected using random sampling schemes (Lecours et al. 2013). Samples presenting SAC are not statistically independent, which can influence standard statistical tests (Moran 1948, Cressie 1993), introducing redundancy into the analyses, and often can induce cross-scale correlation among the variables (Battin \& Lawler 2006, Kristan 2006, Rigby et al. 2010). In species distribution models, SAC of environmental covariates can increase the influence of positional uncertainty in species occurrence data (Moudrý \& Šímová 2012), and artificially increase the performance of models (Veloz 2009, Hijmans 2012). Segurado et al. (2006) demonstrated that SAC inflated the significance estimates of their species distribution models up to 90 -fold.

Several tools can be used to measure and handle SAC (see Zhang et al. 2014). The spatial scale at which SAC occurs needs to be identified to deal with SAC effects. Techniques to identify this scale include spectral analysis (e.g. Legendre \& Demers 1984), study of the 3-term local quadrat variance metric (e.g. Boyce 2006), and neutral landscape models (e.g. With \& King 1997). SAC has a strong potential to help resolve ecological complexities. Legendre (1993) indicates that it should be considered as one of the structural attributes of the landscape that needs to be understood, and not considered only as nuisance. SAC can be an indicator of spatial variability, and can be used to study patchiness as a function of scale across a landscape or seascape (Sokal \& Oden 1978, Sokal 1979). The exploration of the structure of SAC in occurrence data can help improve predictive models by presenting information on the dispersal potential of the organisms (Smith 1994, Araújo \& Williams 2000, Keitt et al. 2002), even more when this is done at multiple scales (Václavík et al. 2012). De Oliveira et al. (2014) showed that accounting for SAC in environmental variables prevents over-fitting of models whilst improving accuracy. Despite its importance, Dormann (2007) found that less than $20 \%$ of species distribution modelling studies accounted for SAC, and most of them focused on trying to remove it, something that cannot be done (Mizon 1995, see discussion in Fortin \& Dale 2009). According to Vierod et al. (2014), none of the species distribution modelling work performed in the deep sea has explicitly considered SAC (e.g. Ross \& Howell 2013). Failure to account for SAC can result in the selection of predictors with the greatest level of autocorrelation (Lennon 2000), the selection of broad-scale predictors over finerscale ones (Diniz-Filho et al. 2003), and selection of models with too many predictors (Hoeting et al. 2006, Latimer et al. 2006). Beale et al. (2007) showed that precision tends to rapidly decrease when SAC increases when using standard non-spatial models. Dormann et al. (2007), Miller et al. (2007), Veloz (2009) and Miller (2012) review SAC in a context of species distribution modelling.

The spatial structure of species distribution is influenced by the autocorrelation among environmental variables (exogenous autocorrelation) and by the autocorrelation among biological variables (endogenous autocorrelation) (Miller 2012). Failing to consider SAC in the analysis and interpretation of data can lead to misinterpretation and incorrect conclusions about spatial structure and the variables that influence it (Lennon 2000, Keitt et al. 2002, Segurado et al. 2006). Incorporating SAC into modelling effort allows additional knowledge to be gained from the analysis, allowing for habitat characterizations that are closer to reality (Hothorn et al. 2011, De Oliveira et al. 2014). Physical and biological processes can be used to generate testable hypotheses concerning change in SAC in benthic habitat structure and benthic fauna (Schneider \& Haedrich 1991). Developments in geostatistical theory now allow prediction of changes in SAC and adaptation of standard statistics for use with spatial data, without violating any IID assumptions. These adaptations often result in better performance than standard statistics when compared on the same datasets (e.g. Brunsdon et al. 1996, Fotheringham et al. 2002, Jombart et al. 2008).

\section{Using spatial statistics to account for spatial heterogeneity}

The interpretation of species-environment relationships and predictive models can be influenced by the choice of statistics used to perform the analysis (Dormann et al. 2007, Finley 2011). Most habitat mapping studies have relied on simple statistics to test species-environment relationships (e.g. Pearson's correlation) before the application of multivariate statistics (Brown et al. 2011a). Multivariate techniques such as linear discriminant function (e.g. McLeod et al. 2007) or principal components analysis (PCA) (e.g. Anderson et al. 2011) allow the inclusion of correlation structure in models and are now more common. With these techniques, the independent variables correspond to the values of environmental covariates at certain point locations corresponding to species occurrences. Often, geographical effects are not considered when statistical analyses are per- 
formed on these points and their associated environmental values, and results are represented nonspatially in tables (e.g. Antunes et al. 2008, Preston 2009). Other works use raster-based statistical analyses where each pixel is considered a sample point (e.g. Maina et al. 2008, Verfaillie et al. 2009). However, despite the fact that pixels are georeferenced, the geographical effects are not taken into consideration in the calculations, but only in the representation of the output maps (Demšar et al. 2013).

Current developments in statistical sciences extend traditional methods to include the spatial component. Locally and geographically weighted statistical methods that account for spatial heterogeneity are becoming increasingly common (Lloyd 2014), particularly in social sciences (e.g. Lloyd 2010a,b), helped by the development of tools for implementation (e.g. the R package GWmodel) (Lu et al. 2014b). Rare examples of their use in marine ecology come from Windle et al. (2010, 2012), who demonstrated that the use of Geographically Weighted Regression (GWR) could improve the detection of interspecies relationships (cod and invertebrates) and speciesenvironment relationships, with identification of the scale(s) at which these relationships were relatively strong. In addition to these methods that consider spatial effects, future developments in geostatistics will likely improve capacity to detect patterns of variations across spatial scales (see Atkinson \& Tate 2000, Zhang et al. 2014). For instance, PardoIgúzquiza \& Dowd (2002) introduced a geostatistical technique (namely a factorial cokriging) to identify how cross-correlation between variables varies with scale.

\section{FUTURE DIRECTIONS - INTEGRATING SPATIAL CONCEPTS IN HABITAT MAPPING}

\section{Past, current and future trends in benthic habitat mapping}

Studies of species-environment relationships often use a limited number of surrogates at either one scale or at multiple arbitrarily chosen scales (Lechner et al. 2012b). Studies of habitats at multiple scales tend to be multi-designed rather than multiscale. While such studies can contribute to our knowledge of marine ecosystems, they may produce results that are not comparable among scales and studies (e.g. because of MAUP) (Mayor et al. 2009, Lechner et al. 2012b). Also, the lower and upper limits of 'useful' scales at which to study benthic habitats are unknown: while there is a belief in the benthic habitat mapping community that finer-scale data will improve the understanding of benthic ecosystems, such an assumption is not necessarily correct as fine-scale data do not always reveal associations present at coarser spatial scales (Schneider et al. 1987).

As highlighted in this review, a multiscale perspective needs to be adopted in benthic habitat mapping (Nash et al. 2014), using objective and non-arbitrary methods to select observational and analytic scales (Wiens 1989, Lechner et al. 2012b). Data collection should be planned to characterize as much as possible of the physical, chemical, and biological environment, with emphasis on those variables relevant to the purpose of the survey. Over the past $10 \mathrm{yr}$, bathymetric LiDAR, acoustic remote sensing, and underwater vehicles have revolutionized how the seafloor environment can be mapped and studied. There are, however, some fundamental technical limitations, such as the footprint size (the size of the area of seafloor surveyed at a particular moment), that will dictate the scale at which the data are available (Kenny et al. 2003, Diaz et al. 2004). These considerations should be integrated in the scale assessment of given studies even though they are often neglected or ignored once the data enter the realm of geographic information systems (GIS) for analysis and map production (Brown et al. 2011a).

The importance of identifying changes in spatial pattern on a continuum has long been recognized in physical and biological oceanography (e.g. Stommel 1963, Steele 1978), and in ecology (Wiens 1989, Levin 1992, Brennan et al. 2002). In terrestrial ecology, Mayor et al. (2009) recommended using a spatial, continuum-based approach to identify the ranges of scales over which organisms associate with their habitat. Advances in spatial statistics (Cressie 1993) put continuum-based analysis on a sound mathematical basis. A continuum-based approach, using coarse-graining, has been applied to benthic transect data (Schneider et al. 1987), but has yet to be implemented in 2-dimensional benthic habitat mapping due to the lack of available data covering a substantial range of scales. The computational power needed to analyze and store such data (Vierod et al. 2014) further limits the application of such approach to quantify the strength of association with habitat as a function of scale. Hierarchical data models could eventually be used to map habitats at multiple scales and implemented in GIS environments so that one habitat map can be represented in different ways depending on the intended application or question. 
The idea of identifying the 'best' or 'right' scale to study habitat association and habitat selection has proven elusive. A logical candidate for 'best' scale is that at which variance in either density or a habitat variable reaches a maximum. However, spectral analyses show no peaks in variance in physical and biological variables in either the pelagic (Horne \& Schneider 1997) or benthic realms (Schneider et al. 1987). Similarly, peaks in the scale at which organisms are associated with habitat are another logical candidate for 'best scale'. Peaks in covariance were not found for any epibenthic species in a study on the outer continental shelf of Newfoundland (Schneider et al. 1987) and have yet to be reported in subsequent studies. Competing with the idea of 'right' scale, Wiens (1989) introduced the concept of scale domains, which he defined as ranges of continuous scales for which there is no change (or a constant change) in the observed pattern or process and separated by 'chaotic' transitions (see Fig. 4 in Wiens 1989). He argued that these domains were key to

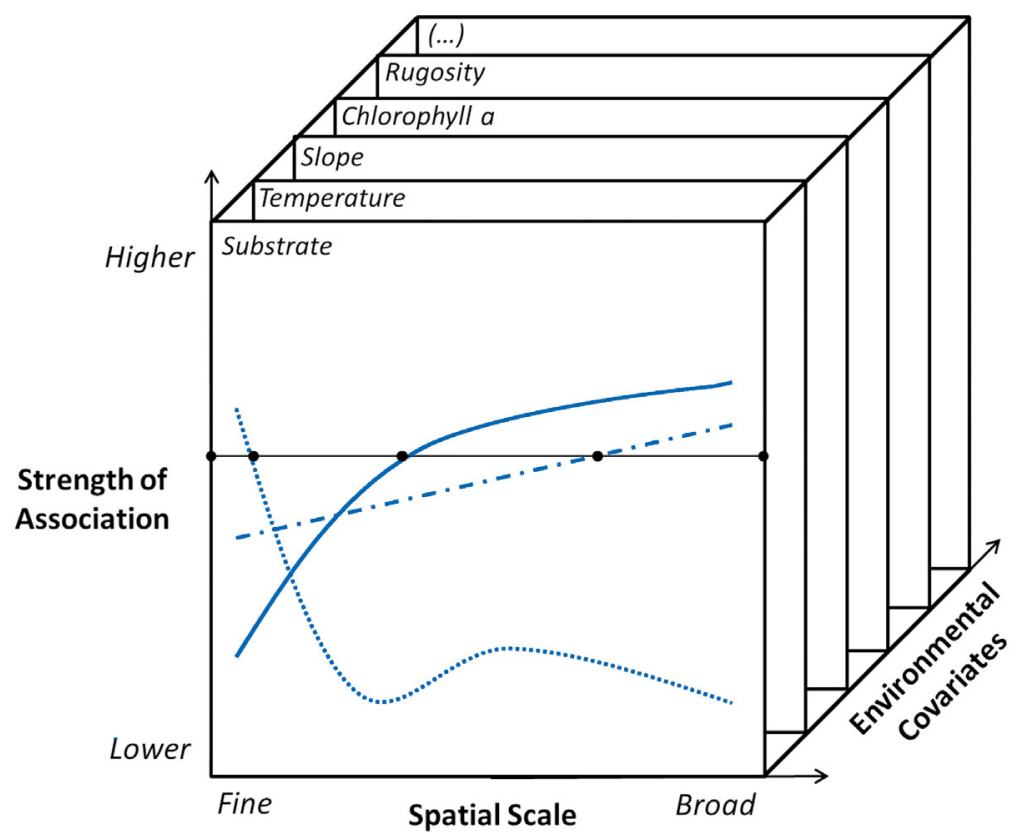

Fig. 4. Conceptual representation of the implementation of a continuum-based multiscale approach to explore scale-dependency of species-environment relationships. By sampling several environmental characteristics ( $z$ axis) at multiple spatial scales ( $x$ axis), it is possible to quantify the strength of association ( $y$ axis) between a species and its habitat as a function of scale (blue curves). The black horizontal line represents a given significance threshold. Note that if a coefficient of correlation was to be used to measure significance, there would be 2 significance thresholds: one for strongly positive correlations and one for strongly negative correlations. Curves are hypothetical and inspired by results from Horne \& Schneider (1997) (pelagic species), and Schneider et al. (1987) and Kendall et al. (2011) (benthic and epibenthic species) understanding ecological systems and could define the limits of generalizations (i.e. the bounds within which it is possible to scale-up or scale-down). Scale domains, as defined graphically by Wiens (1989), have not yet been confirmed by empirical data. Graphic representations of patterns and processes as a function of resolution scale in a benthic context (Schneider et al. 1987, Schneider \& Haedrich 1991) show a variety of patterns, with no evidence of transitions as depicted by Wiens (1989). The term 'scale domain' has however been used by other authors to characterize levels in hierarchical theory and modelling frameworks (e.g. Wu 1999, Pearson \& Dawson 2003, Muñoz-Reinoso 2009). The concept of 'scaledependent pattern and process' is arguably of more utility in habitat mapping than attempts to 'detect the right scale' or identify 'scale domains'. Scaling manoeuvres (Schneider 2001b), in either the distance domain (e.g. lagging) or frequency domain (e.g. coarse-graining) are available for characterizing the association of benthic biota with habitat, and quantifying habitat association as a function of scale. Fig. 4 illustrates how such techniques can be implemented by quantifying the association between a species and several characteristics of its environment at multiple scales.

Because benthic habitats are being altered or destroyed at a faster pace than we discover and understand them (Ramirez-Llodra et al. 2011), it becomes urgent to make effective use of resources to map benthic habitats. Identifying useful surrogates will become possible as this field shifts from studies at multiple scales that only tell part of the story, to continuum-based multiscale approaches. When studying species-habitat relationships, it is as important to identify the scales at which environmental factors drive species distributions as to identify the relevant environmental factors (Williams et al. 2012, Mateo Sánchez et al. 2014). Sampling should be planned with a full combination of efforts to survey as many characteristics of the environment as possible and at as many scales as possible. Because all species cannot be studied, species assemblages (e.g. Howell et al. 2010) or those species that interact strongly with other species (e.g. Buhl-Mortensen et al. 2010, Baker et al. 2012), or that modify/ create habitats (engineer species) (e.g. Howell et al. 2011), or that serve as umbrella species in a conservation context (Larsen \& Rahbek 2005), should be targeted. Techniques 
such as bivariate scaling (e.g. Mateo Sánchez et al. 2014), spectral analysis (e.g. Schneider et al. 1987), or scalewise variance (e.g. Detto \& Muller-Landau 2013) could then be used to identify the strength of association of a particular species with habitat variables at multiple scales. Muotka et al. (1998) demonstrated how geostatistics can be efficiently used to characterize the spatial associations between lotic fish and macroinvertebrate species and their habitat at multiple scales while avoiding MAUP effects. Geostatistics and spatial analysis also include methods to deal with the concept of fuzzy boundaries, which are characteristic of many habitats (Dale \& Fortin 2014). The problem is rarely acknowledged in the practice of habitat mapping, which typically imposes sharp boundary delineation.

Benthic ecosystem research often lacks sufficiently extensive datasets at several scales, particularly in the deep sea where sampling is limited and sporadic (Benn et al. 2010). Current data acquisition techniques often cannot capture biological and environmental patterns and processes at a fine resolution over extensive areas (Wilson et al. 2007, Huang et al. 2012), resulting in the need to identify tools to fill the gap. Ongoing improvements in bathymetric LiDAR and multibeam echosounders data analysis are generating some of the most extensive and accurate seafloor data available (Costa et al. 2009, Schimel et al. 2010). Development of remotely operated vehicles (ROV) and autonomous underwater vehicles (AUV) has increased both the range and extent of seafloor data (Wright 1999, Heyman \& Wright 2011) at ever decreasing costs per megabyte. ROV- and AUVmounted sensors have the capacity to sample the chemical, physical, and biological environment at fine spatial scales. These new technologies allow biological, geological, chemical, and physical observations to be situated in an accurate multiscale and geospatial context, allowing identification of surrogate variables (e.g. Costa et al. 2014, see Van Rein et al. 2009). Metadata are essential to improve the use of geospatial data and to build what Devillers et al. (2007) call a 'quality-aware' community: all collected datasets will need to be associated with complete metadata files reporting scale information, error and uncertainty quantification, the species or environmental variables that were targeted, the other species that were observed, and other information relevant to further use of the datasets.

Technological developments will continue to drive progress in benthic habitat mapping. Of interest are developments in automatic species detection and analysis on video data (e.g. Purser et al. 2009, Lüdtke et al. 2012, Seiler et al. 2012, Tanner et al. 2015), in methods for generating photo-mosaics of the seafloor for accurate georeferencing (e.g. Prados et al. 2012, Kwasnitschka et al. 2013, Marsh et al. 2013), in spatial statistics (e.g. Harris et al. 2011, Lu et al. 2014a,b), in computationally fast algorithms capable of processing high-dimensional datasets (e.g. Mumby 2006, Filzmoser et al. 2008, Bermejo et al. 2011, Oyana et al. 2012), in species distribution models that consider spatial autocorrelation, non-stationarity, and scale (e.g. Miller \& Hanham 2011, Robinson et al. 2011, Beale et al. 2014, Vierod et al. 2014), and in geomorphometry (Gessler et al. 2009, Guth 2013). Analyses at multiple scales with many datasets require substantial computational time and effort, and tools that can iterate analyses at multiple scales will become necessary. Surveying multiple characteristics of an area at multiple scales generates immense amounts of data. As in satellite remote sensing (Turner et al. 2015), adequate software and institutional arrangements are needed to realize the potential for these data to be used for purposes other than habitat mapping, to become a valued repository (Borja 2014), and to notify stakeholders of their existence. This resource-sharing philosophy is important to implement (Turner et al. 2015) if marine scientists are to make effective use of the data and to understand benthic ecosystems before they become substantially altered (Vierod et al. 2014). In some cases, data have been stored for decades waiting for the development of appropriate analytical tools (Knobles et al. 2008). Conversely some researchers might have developed tools applicable to more than their own application, but lack the platform to share these tools with the relevant communities.

\section{Improving standards for defining benthic habitats}

In the previous sections we review the ways that scale and the spatial nature of data influence the way we perceive, measure, analyze, and interpret the environment and species-habitat relationships in benthic habitats. We found that information on scale is not always clearly reported in published works, that a quantitative understanding of habitats and scale is needed, and that results depend on the geographic context of habitat mapping. We thus propose a better standard for defining benthic habitat, one that builds upon the habitat definition of Harris \& Baker (2012a). With these standards benthic habitats can be defined as 'areas of seabed that are (geo)statistically significantly different from 
their surroundings in terms of physical, chemical and biological characteristics, when observed at particular spatial and temporal scales'. This revised definition of benthic habitat addresses some of the critiques discussed in the previous sections. First, it addresses the growing realization that habitats must be quantitatively delineated and that what constitutes the description of a habitat is dictated by the scale of the techniques employed (Diaz et al. 2004). Then, it addresses the argument for considering the chemical environment in the characterization of benthic habitats (Kostylev et al. 2001, Brown et al. 2011a). Finally, it addresses the case made by Cogan \& Noji (2007) that habitats be placed in context with the appropriate spatial, temporal and thematic scales when being mapped. The reference to geostatistics encompasses the consideration of the spatial nature of data and the concepts of fuzzy boundary delineation, while the biological characteristics relate to thematic scale and allow the study of species assemblages as much as individual species, and the mention of spatial and temporal scales makes habitats explicit about scale. Being explicit about temporal scale is important when studying migratory species that do not inhabit the same space through time.

\section{Recommendations}

The previous section on trends in benthic habitat mapping highlighted some of the main issues currently encountered in benthic habitat mapping, proposed some solutions and gave an insight on what the future developments might bring to the field. Based on this discussion, it is possible to identify 3 elements in the habitat mapping process that can be improved: project planning and data collection, data analysis and interpretation, and communication/dissemination of research results and data. Project planning and data collection can be improved from a biological, environmental and/or approach point of view. For the biology, we recommend focusing on the study of ecosystem engineer or umbrella species that would indirectly allow collecting data on other species. For the environment, we recommend sampling as many environmental variables as possible to aim for a comprehensive understanding of the environment and its dynamics. In terms of approach, we recommend adopting continuum-based multiscale methods, which involves sampling the environment over an extensive range of spatial scales. To improve data analysis and interpretation, we recom- mend using spatial statistical analyses that consider spatial heterogeneity and autocorrelation of data, rather than standard statistics based on the assumptions of IID, to establish results on a sound inferential basis. We also suggest always quantifying errors and spatial uncertainty. Finally, to improve communication and dissemination of research and data, we recommend making available metadata in which the results from the quantification of errors would be reported together with the spatial scales at which the data was collected (observation scale), at which the research was intended to be conducted (ecological scale), and at which the analysis was performed (analysis scale). In terms of dissemination, we suggest developing and automating tools (e.g. GIS, statistical, ecological) for processing or analyzing data and make them available, together with datasets and complete metadata, to maximize research and application potential.

\section{CONCLUSIONS}

Organisms inhabit a space that suits their needs. Understanding what controls benthic species distribution requires understanding the physico-chemical properties and dynamics within the water column, and at the seafloor interface (Clark et al. 2012, Vierod et al. 2014). The structure and spatial arrangement of habitats constrain, and can potentially become predictors of, species distribution, abundance, and richness. The cost and difficulties associated with sampling the marine environment highlight the need for better predictions of species distributions and improvement in sampling strategies. This will become possible with a better understanding of ecological patterns and processes as a function of scale, and should bring an overall improvement to benthic research efficiency. Using appropriate surrogates at appropriate scales is likely to be more effective than the use of opportunistic or arbitrarily chosen variables and scales. Generating habitat maps is a complex process that requires multidisciplinary efforts (Heyman \& Wright 2011). Technological advances will help marine scientists address the current challenges of their field and develop new approaches to understand and so protect benthic habitat structure and function (Ramirez-Llodra et al. 2011). Geospatial data and techniques from geomatics and geostatistics show potential to tackle core issues in spatial ecology (Skidmore et al. 2011, Laffan et al. 2012) and in the marine sciences (Wright \& Goodchild 1997, Heyman \& Wright 2011). 
The need for fundamental ecological and conservation theory, including explicit treatment of spatial scale has been noted repeatedly (e.g. Guisan \& Thuiller 2005, Levin \& Dayton 2009). Spatial scale is central to understanding habitat use, to selecting a sampling method, and to statistical analysis. Despite being recognized as a central issue, scales are often arbitrarily chosen, and studies regularly fail to report the scale(s) investigated and how the results depend on spatial scale. As stated by Dungan et al. (2002, p. 632): 'If ecologists are explicit about all of the components and dimensions of scale so that the spatial characteristics of the quantities measured can be correctly interpreted, there will be new opportunities to gain experience and improve understanding of the effects of observations and analysis scale changes.' Evidence-based scaling functions, which link pattern to process as a function of scale, are needed to identify reliable surrogates of species distribution, to scale-up and scale-down relevant information, and for improved quantitative understanding of benthic habitats.

Based on this review, we provide 8 recommendations that could lead to more efficient practices in benthic habitat mapping: (1) umbrella species' habitats should be prioritized for mapping and prediction; (2) sampling should be conducted to obtain data covering an extensive range of spatial scales and as many environmental variables as possible; (3) continuum-based habitat characterization approaches should be adopted; (4) statistical methods that consider the spatial nature of data should systematically be used; (5) errors and spatial uncertainty should be quantified at every step of habitat mapping (i.e. data collection, surrogacy testing, predictive modelling); (6) existing tools should be automated and new tools (e.g. GIS, statistical, ecological) should be developed for processing data and defining surrogates of species distribution and habitat at multiple scales; (7) data, complete metadata, and tools should be made available to maximize research and applications potential; and (8) the spatial extent and resolution (scale) at which the research was intended to be conducted, at which the data was collected, and at which predictive or monitoring aims were directed should always be clearly reported. We further recommend that benthic habitat be defined to the following standards: (1) explicit statement of observational scale (i.e. spatial resolution and extent); (2) inclusion of chemical variables along with physical and biological variables; and (3) placement in context with the appropriate spatial, temporal and thematic scales when being mapped.
Acknowledgements. Thanks to Emma LeClerc, Katherine Macpherson and Emilie Novaczek for their insightful comments on early versions of this manuscript, and to 3 anonymous reviewers. We also acknowledge the National Sciences and Engineering Research Council of Canada (NSERC) and the Department of Fisheries and Oceans Canada for their financial support. Authors are listed by order of contribution.

\section{LITERATURE CITED}

Adams DK, Flieri GR (2010) Modeled interactions of mesoscale eddies with the East Pacific Rise: implications for larval dispersal. Deep-Sea Res I 57:1163-1176

Addicott JF, Aho JM, Antolin MF, Padilla MF, Richardson JS, Soluk DA (1987) Ecological neighborhoods: scaling environmental patterns. Oikos 49:340-346

Anderson TJ, Yoklavich MM (2007) Multiscale habitat associations of deepwater demersal fishes off central California. Fish Bull 105:168-179

Anderson DP, Turner MG, Forester JD, Zhu J, Boyce MS, Beyer H, Stowell L (2005) Scale-dependent summer resource selection by reintroduced elk in Wisconsin, USA. J Wildl Manag 69:298-310

Anderson JT, Holliday DV, Kloser R, Reid DG, Simard Y (2008) Acoustic seabed classification: current practice and future directions. ICES J Mar Sci 65:1004-1011

Anderson TJ, Nichol SL, Syms C, Przeslawski R, Harris PT (2011) Deep-sea bio-physical variables as surrogates for biological assemblages, and example from the Lord Howe Rise. Deep-Sea Res II 58:979-991

Antunes SC, Pereira E, Sousa JP, Santos MC, Gonçales F (2008) Spatial and temporal distribution of litter arthropods in different vegetation covers of Porto Santo Island. Eur J Soil Biol 44:45-56

Apps CD, McLellan BN, Kinley T, Flaa JP (2001) Scaledependent habitat selection by mountain caribou, Columbia Mountains, British Columbia. J Wildl Manag 65: 65-77

Araújo MB, Guisan A (2006) Five (or so) challenges for species distribution modelling. J Biogeogr 33:1677-1688

> Araújo MB, Williams PH (2000) Selecting areas for species persistence using occurrence data. Biol Conserv 96: 331-345

Atkinson PM, Tate NJ (2000) Spatial scale problems and geostatistical solutions: a review. Prof Geogr 52:607-623

- Austin MP (2002) Spatial prediction of species distribution: an interface between ecological theory and statistical modelling. Ecol Model 157:101-118

Austin MP, Van Niel KP (2011) Improving species distribution models for climate change studies: variable selection and scale. J Biogeogr 38:1-8

Baillon S, Hamel JF, Wareham VE, Mercier A (2012) Deep cold-water corals as nurseries for fish larvae. Front Ecol Environ 10:351-356

Baker KD, Haedrich RL, Fifield DA, Gilkinson KD (2012) Grenadier abundance examined at varying spatial scales in deep waters off Newfoundland, Canada, with special focus on the influence of corals. J Ichthyol 52:678-689

> Barry S, Elith J (2006) Error and uncertainty in habitat models. J Appl Ecol 43:413-423

Battin J, Lawler JJ (2006) Cross-scale correlations and the design and analysis of avian habitat selection studies. Condor 108:59-70 
Beale CM, Lennon JJ (2012) Incorporating uncertainty in predictive species distribution modelling. Philos Trans R Soc B Biol Sci 367:247-258

Beale CM, Lennon JJ, Elston DA, Brewer MJ, Yearsley JM (2007) Red herrings remain in geographical ecology: a reply to Hawkin et al. (2007). Ecography 30:845-847

Beale CM, Lennon JJ, Yearsley JM, Brewer MJ, Elston DA (2010) Regression analysis of spatial data. Ecol Lett 13: 246-264

Beale CM, Brewer MJ, Lennon JJ (2014) A new statistical framework for the quantification of covariate associations with species distributions. Methods Ecol Evol 5: 421-432

Benaka L (ed) (1999) Fish habitat: essential fish habitat and rehabilitation. American Fisheries Society, Bethesda, $\mathrm{MD}$

Benn AR, Weaver PP, Billett DSM, Van den Hove S, Murdock AP, Doneghan GB, Le Bas T (2010) Human activities on the deep seafloor in the North East Atlantic: an assessment of spatial extent. PLoS ONE 5:e12730

Bermejo P, Gámez JA, Puerta JM (2011) A GRASP algorithm for fast hybrid (filter-wrapper) feature subset selection in high-dimensional datasets. Pattern Recognit Lett 32: 701-711

Borja A (2014) Grand challenges in marine ecosystems ecology. Front Mar Sci 1:1-6

> Boström C, Pittman SJ, Simenstad C, Kneib RT (2011) Seascape ecology of coastal biogenic habitats: advances, gaps, and challenges. Mar Ecol Prog Ser 427:191-217

- Boyce MS (2006) Scale for resource selection functions. Divers Distrib 12:269-276

Braunisch V, Suchant R (2010) Predicting species distributions based on incomplete survey data: the trade-off between precision and scale. Ecography 33:826-840

Brennan JM, Bender DJ, Contreras TA, Fahrig L (2002) Focal patch landscape studies for wildlife management: optimizing sampling effort across scales. In: Liu J, Taylor WW (eds) Integrating landscape ecology into natural resource management. Cambridge University Press, Cambridge, p 68-91

> Brock JC, Wright CW, Clayton TD, Nayegandhi A (2004) LIDAR optical rugosity of coral reefs in Biscayne National Park, Florida. Coral Reefs 23:48-59

Brown CJ, Todd BJ, Kostylev VE, Pickrill RA (2011B) Imagebased classification of multibeam sonar backscatter data for objective surficial sediment mapping of Georges Bank, Canada. Cont Shelf Res 31:S110-S119

Brown CJ, Smith SJ, Lawton P, Anderson JT (2011a) Benthic habitat mapping: a review of progress towards improved understanding of the spatial ecology of the seafloor using acoustic techniques. Estuar Coast Shelf Sci 92:502-520

Brown CJ, Sameoto JA, Smith SJ (2012) Multiple methods, maps, and management applications: purpose made seafloor maps in support of ocean management. J Sea Res 72:1-13

Brunsdon C, Fotheringham AS, Charlton ME (1996) Geographically weighted regression: a method for exploring spatial nonstationarity. Geogr Anal 35:58-82

- Bryan TL, Metaxas A (2007) Predicting suitable habitat for deep-water gorgonian corals on the Atlantic and Pacific Continental Margins of North America. Mar Ecol Prog Ser 330:113-126

Buhl-Mortensen L, Vanreusel A, Gooday AJ, Levin LA and others (2010) Biological structures as a source of habitat heterogeneity and biodiversity on the deep ocean margins. Mar Ecol 31:21-50

Carr MH, Neigel JE, Estes JA, Andelman SJ, Warner RR, Largier JL (2003) Comparing marine and terrestrial ecosystems: implications for the design of coastal marine reserves. Ecol Appl 13(Suppl):90-107

Clark WC (1985) Scales of climatic impacts. Clim Change 7: $5-27$

> Clark MR, Schlacher TA, Rowden AA, Stocks KI, Consalvey M (2012) Science priorities for seamounts: research links to conservation and management. PLoS ONE 7:e29232

Clarke A, Lidgard S (2000) Spatial patterns of diversity in the sea: bryozoan species richness in the North Atlantic. J Anim Ecol 69:799-814

Cogan CB, Noji TT (2007) Marine classification, mapping, and biodiversity analysis. In: Todd BJ, Greene HG (eds) Mapping the seafloor for habitat characterization. Geol Assoc Can Spec Pap 47:129-139

Coggan R, Populis J, White J, Sheehan K, Fitzpatrick F, Piel $\mathrm{S}$ (eds) (2007) Review of standards and protocols for seabed habitat mapping, 2nd edn. MESH (Mapping European Seabed Habitats). www.emodnet-seabedhabitats. eu/default.aspx?page $=1442$

> Conroy MJ, Noon BR (1996) Mapping of species richness for conservation of biological diversity: conceptual and methodological issues. Ecol Appl 6:763-773

Cook R, Fariñas-Franco JM, Gell FR, Holt RHF and others (2013) The substantial first impact of bottom fishing on rare biodiversity hotspots: a dilemma for evidence-based conservation. PLoS ONE 8:e69904

Copeland A, Edinger E, Bell T, LeBlanc P, Wroblewski J, Devillers R (2012) Geomorphic features and benthic habitats of a sub-Arctic fjord: Gilbert Bay, Southern Labrador, Canada. In: Harris PT, Baker EK (eds) Seafloor geomorphology as benthic habitats: GeoHab atlas of seafloor geomorphic features and benthic habitats. Elsevier, Amsterdam, p 309-327

Costa BM, Battista TA, Pittman SJ (2009) Comparative evaluation of airborne LiDAR and ship-based multibeam SoNAR bathymetry and intensity for mapping coral reef ecosystems. Remote Sens Environ 113:1082-1100

Costa B, Taylor JC, Kracker L, Battista T, Pittman S (2014) Mapping reef fish and the seascape: using acoustics and spatial modeling to guide coastal management. PLoS ONE 9:e85555

Cressie N (1993) Statistics for spatial data. Wiley, New York, NY

Cressie N, Wikle CK (2011) Statistics for spatio-temporal data. Wiley, Hoboken, NJ

Dale MRT, Fortin MJF (2014) Spatial analysis: a guide for ecologists (2nd edn). Cambridge University Press, Cambridge

Davies AJ, Guinotte JM (2011) Global habitat suitability for framework-forming cold-water corals. PLoS ONE 6: e18483

> Davies AJ, Wisshak M, Orr JC, Murray Roberts J (2008) Predicting suitable habitats for the cold-water coral Lophelia pertusa (Scleractinia). Deep-Sea Res I 55:1048-1062

$>$ De Knegt HJ, Van Langevelde F, Coughenour MB, Skidmore AK and others (2010) Spatial autocorrelation and the scaling of species-environment relationships. Ecology 91:2455-2465

De Leo FC, Vetter EW, Smith CR, Rowden AA, McGranaghan M (2014) Spatial scale-dependent habitat heterogeneity influences submarine canyon macrofaunal abundance and diversity off the Main and Northwest 
Hawaiian Islands. Deep-Sea Res II 104:267-290

De Oliveira G, Rangel TF, Lima-Ribeiro MS, Terribile LC, Diniz-Filho JAF (2014) Evaluating, partitioning, and mapping the spatial autocorrelation component in ecological niche modeling: a new approach based on environmentally equidistant records. Ecography 37:637-647

> Delcourt HR, Delcourt PA, Webb T (1983) Dynamic plant ecology: the spectrum of vegetational change in space and time. Quat Sci Rev 1:153-175

Demšar U, Harris P, Brunsdon C, Fotheringham AS, McLoone S (2013) Principal component analysis on spatial data: an overview. Ann Assoc Am Geogr 103: 106-128

> Deng Y, Wilson JP, Bauer BO (2007) DEM resolution dependencies of terrain attributes across a landscape. Int J Geogr Inf Sci 21:187-213

> Detto M, Muller-Landau HC (2013) Fitting ecological process models to spatial patterns using scalewise variances and moment equations. Am Nat 181:E68-E82

Devillers R, Bédard Y, Gervais M, Jeansoulin R and others (2007) How to improve geospatial data usability: from metadata to quality-aware GIS community. In: Wachowicz M, Bodum L (eds) Spatial data usability, an AGILE pre-conference workshop. Proceedings of the 10th AGILE International Conference on Geographic Information Science, Aalborg, May 8. AGILE (Association of Geographic Information Laboratories in Europe), p 1-8

$>$ Diaz RJ, Solan M, Valente RM (2004) A review of approaches for classifying benthic habitats and evaluating habitat quality. J Environ Manag 73:165-181

> Diniz-Filho JAF, Bini LM, Hawkins BA (2003) Spatial autocorrelation and red herrings in geographical ecology. Glob Ecol Biogeogr 12:53-64

> Dolan MFJ, Lucieer VL (2014) Variation and uncertainty in bathymetric slope calculations using geographic information systems. Mar Geod 37:187-219

> Dormann CF (2007) Effects of incorporating spatial autocorrelation into the analysis of species distribution data. Glob Ecol Biogeogr 16:129-138

> Dormann CF, McPherson JM, Araújo MB, Bivand R and others (2007) Methods to account for spatial autocorrelation in the analysis of species distributional data: a review. Ecography 30:609-628

Dormann CF, Elith J, Bacher S, Buchmann C and others (2013) Collinearity: a review of methods to deal with it and a simulation study evaluating their performance. Ecography 36:27-46

Drăgut L, Eisank C, Strasser T, Blaschke T (2009) A comparison of methods to incorporate scale in geomorphometry. In: Purves R, Gruber S, Straumann R, Hengl T (eds) Geomorphometry 2009 Conf Proc. University of Zürich, Switzerland, p 133-139

> Dungan JL, Perry JN, Dale MRT, Legendre P and others (2002) A balanced view of scale in spatial statistical analysis. Ecography 25:626-640

> Dunn DC, Halpin PN (2009) Rugosity-based regional modeling of hard-bottom habitat. Mar Ecol Prog Ser 377:1-11

$>$ Dutilleul P, Legendre P (1993) Spatial heterogeneity against heteroscedasticity: an ecological paradigm versus a statistical concept. Oikos 66:152-171

> Edinger EN, Sherwood OA, Piper DJW, Wareham VE, Baker KD, Gilkinson KD, Scott DB (2011) Geological features supporting deep-sea coral habitat in Atlantic Canada. Cont Shelf Res 31:S69-S84

Elith J, Leathwick JR (2009) Species distribution models: ecological explanation and prediction across space and time. Annu Rev Ecol Evol Syst 40:677-697

Engler R, Guisan A, Rechsteiner L (2004) An improved approach for predicting the distribution of rare and endangered species from occurrence and pseudo-absence data. J Appl Ecol 41:263-274

> Etnoyer P, Morgan LE (2007) Predictive habitat model for deep gorgonian needs better resolution: Comment on Bryan \& Metaxas (2007). Mar Ecol Prog Ser 339:311-312

Evans IS (1972) General geomorphometry, derivatives of altitude, and descriptive statistics. In: Chorley RJ (ed) Spatial analysis in geomorphology. Harper \& Row, London, p 17-90

Fassnacht KS, Cohen WB, Spies TA (2006) Key issues in making and using satellite-based maps in ecology: a primer. For Ecol Manag 222:167-181

Filzmoser P, Maronna R, Werner M (2008) Outlier identification in high dimensions. Comput Stat Data Anal 52: 1694-1711

> Finley AO (2011) Comparing spatially-varying coefficients models for analysis of ecological data with non-stationarity and anisotropic residual dependence. Methods Ecol Evol 2:143-154

Florinsky IV, Kuryakova GA (2000) Determination of grid size for digital terrain modelling in landscape investigations - exemplified by soil moisture distribution scale. Int J Geogr Inf Sci 14:815-832

> Foody GM (2004) Spatial nonstationarity and scale-dependency in the relationship between species richness and environmental determinants for the sub-Saharan endemic avifauna. Glob Ecol Biogeogr 13:315-320

Fortin MJ, Dale MR (2009) Spatial autocorrelation in ecological studies: a legacy of solutions and myths. Geogr Anal 41:392-397

Fortin MJ, Keith TH, Maurer BA, Taper ML, Kaufman DM, Blackburn TM (2005) Species' geographic ranges and distributional limits: pattern analysis and statistical issues. Oikos 108:7-17

Fotheringham AS, Brunsdon C, Charlton M (2002) Geographically weighted regression: the analysis of spatially varying relationships. Wiley, Chichester

Franklin J (2009) Mapping species distributions: spatial inference and prediction. Cambridge University Press, Cambridge

Freeman SM, Rogers SI (2003) A new analytical approach to characterisation of macro-epibenthic habitats: linking species to the environment. Estuar Coast Shelf Sci 56: 749-764

Freitas R, Ricardo F, Pereira F, Sampaio L and others (2011) Benthic habitat mapping: concerns using a combined approach (acoustic, sediment and biological data). Estuar Coast Shelf Sci 92:598-606

Gage JD, Tyler PA (1999) Deep-sea biology: a natural history of organisms at the deep-sea floor. Cambridge University Press, Cambridge

Gallucci F, Moens T, Fonesca G (2009) Small-scale patterns of meibenthos in the Arctic deep sea. Mar Biodivers 39: 9-25

Galparsoro I, Borja A, Uyarra MC (2014) Mapping ecosystem services provided by benthic habitats in the European North Atlantic Ocean. Front Mar Sci 1:23-36

Gambi C, Danovaro R (2006) A multiple-scale analysis of metazoan meiofaunal distribution in the deep Mediterranean Sea. Deep-Sea Res 53:1117-1134

García D, Ortiz-Pulido R (2004) Patterns of resource tracking 
by avian frugivores at multiple spatial scales: two case studies on discordance among scales. Ecography 27: 187-196

Gehlke CE, Biehl K (1934) Certain effects of grouping upon the size of the correlation coefficient in census tract material. J Am Stat Assoc 29:169-170

Georgian SE, Shedd W, Cordes EE (2014) High-resolution ecological niche modelling of the cold-water coral Lophelia pertusa in the Gulf of Mexico. Mar Ecol Prog Ser 506:145-161

Gessler P, Pike R, MacMillan RA, Hengl T, Reuter HI (2009) The future of geomorphometry. In: Hengl T, Reuter HI (eds) Geomorphometry: concepts, software, applications. (Developments in soil science 33). Elsevier Science, Amsterdam, p 637-652

Gjerde KM (2006) Ecosystems and biodiversity in deep waters and high seas. UNEP Regional Seas Reports and Studies 178, UNEP/IUCN, Gland

Goodchild MF (2004) The validity and usefulness of laws in geographic information science and geography. Ann Assoc Am Geogr 94:300-303

Goodchild MF (2011) Scale in GIS: an overview. Geomorphology 130:5-9

Grabowski JH, Bachman M, Demarest C, Eayrs S and others (2014) Assessing the vulnerability of marine benthos to fishing gear impacts. Rev Fish Sci Aquacult 22:142-155

Gray JS (1966) Selection of sands by Protodrilus symbioticus (Giard). Veroeff Inst Meeresforsch Bremerhav 2:106-116

Greene HG, Bizzarro JJ, O'Connell VM, Brylinsky CK (2007) Construction of digital potential marine benthic habitat maps using a coded classification scheme and its application. In: Todd BJ, Greene HG (eds) Mapping the seafloor for habitat characterization. Geol Assoc Can Spec Pap 47:141-155

Greig-Smith P (1952) The use of random and contiguous quadrants in the study of the structure and plant communities. Ann Bot 16:293-316

> Grober-Dunsmore R, Frazer TK, Lindberg WJ, Beets J (2007) Reef fish and habitat relationships in a Caribbean seascape: the importance of reef context. Coral Reefs 26: 201-216

Guisan A, Thuiller W (2005) Predicting species distribution: offering more than simple habitat models. Ecol Lett 8: 993-1009

Guisan A, Graham CH, Elith J, Huettmann F, NCEAS Species Distribution Modelling Group (2007) Sensitivity of predictive species distribution models to change in grain size. Divers Distrib 13:332-340

Gustafson E (1998) Quantifying landscape spatial pattern: What is the state of the art? Ecosystems 1:143-156

Guth PL (2013) The giga revolution in geomorphometry: gigabytes of RAM, gigabyte-sized data sets, and gigabit internet access. In: Guoan T, Qiming Z, Mitasova H, Hengl T (eds) Geomorphometry 2013 Conf Proc, Nanjing Normal University, China, October 16-20. Nanjing Normal University, Nanjing, p K41-K44

Hagberg J, Jonzén N, Lundberg P, Ripa J (2003) Uncertain biotic and abiotic interactions in benthic communities. Oikos 100:353-361

Halpern BS, Walbridge S, Selkoe KA, Kappel CV and others (2008) A global map of human impact on marine ecosystems. Science 319:948-952

Hanberry BB (2013) Finer grain size increases effects of error and changes influence of environmental predictors on species distribution models. Ecol Inform 15:8-13
Harris PT (2012) Anthropogenic threats to benthic habitats. In: Harris PT, Baker EK (eds) Seafloor geomorphology as benthic habitats: GeoHab atlas of seafloor geomorphic features and benthic habitats. Elsevier, Amsterdam, p 39-60

Harris PT, Baker EK (2012a) Why map benthic habitats? In: Harris PT, Baker EK (eds) Seafloor geomorphology as benthic habitats: GeoHab atlas of seafloor geomorphic features and benthic habitats. Elsevier, Amsterdam, p 3-22

Harris PT, Baker EK (eds) (2012b) Seafloor geomorphology as benthic habitats: GeoHab atlas of seafloor geomorphic features and benthic habitats. Elsevier, Amsterdam

Harris P, Brunsdon C, Charlton M (2011) Geographically weighted principal components analysis. Int J Geogr Inf Sci 25:1717-1736

Harvey F (2008) A primer of GIS: fundamental geographic and cartographic concepts. The Guilford Press, New York, NY

Haury LR, McGowan JA, Wiebe PH (1978) Patterns and processes in the time-space scales of plankton distributions. In: Steele JH (ed) Spatial pattern in plankton communities. Plenum Press, New York, NY, p 277-327

Hengl T (2006) Finding the right pixel size. Comput Geosci 32:1283-1298

Hengl T, MacMillan RA (2009) Geomorphometry - a key to landscape mapping and modelling. In: Hengl T, Reuter HI (eds) Geomorphometry: concepts, software, applications. (Developments in soil science 33). Elsevier Science, Amsterdam, p 433-460

Henry LA, Moreno Navas J, Roberts JM (2013) Multi-scale interactions between local hydrography, seabed topography, and community assembly on cold-water coral reefs. Biogeosciences 10:2737-2746

Heyman WD, Wright DJ (2011) Focus: marine geomorphology as a determinant for essential life habitat and marine protected area design. Prof Geogr 63:429-442

Heywood ID, Cornelius S, Carver S (2006) An introduction to geographic information systems, 3rd edn. Pearson Education Limited, Harlow

> Hijmans RJ (2012) Cross-validation of species distribution models: removing spatial sorting bias and calibration with a null model. Ecology 93:679-688

Hill NA, Lucieer V, Barrett NS, Anderson TJ, Williams SB (2014) Filling the gaps: predicting the distribution of temperate reef biota using high resolution biological and acoustic data. Estuar Coast Shelf Sci 147:137-147

> Hitt S, Pittman SJ, Nemeth RS (2011) Diel movements of fishes linked to benthic seascape structure in a Caribbean coral reef ecosystem. Mar Ecol Prog Ser 427: 275-291

Hobbs NT (2003) Challenges and opportunities in integrating ecological knowledge across scales. For Ecol Manag 181:223-238

> Hoeting JA, Davis RA, Merton AA, Thompson SE (2006) Model selection for geostatistical models. Ecol Appl 16: 87-98

> Horne JK, Schneider DC (1997) Spatial variance of mobile marine organisms: capelin and cod in Newfoundland coastal waters. Philos Trans R Soc Lond B Biol Sci 352: 633-642

> Hothorn T, Müller J, Schröder B, Kneib T, Brandl R (2011) Decomposing environmental, spatial, and spatiotemporal components of species distributions. Ecol Monogr 81: $329-347$ 
Howell KL (2010) A benthic classification system to aid in the implementation of marine protected area networks in the deep/high seas of the NE Atlantic. Biol Conserv 143: 1041-1056

> Howell KL, Davies JS, Narayanaswamy BE (2010) Identifying deep-sea megafaunal epibenthic assemblages for use in habitat mapping and marine protected area network design. J Mar Biol Assoc UK 90:33-68

Howell KL, Holt R, Endrino IP, Stewart H (2011) When the species is also a habitat: comparing the predictively modelled distribution of Lophelia pertusa and the reef habitat it forms. Biol Conserv 144:2656-2665

> Huang Z, Nichol SL, Siwabessy JPW, Daniell J, Brooke BP (2012) Predictive modelling of seabed sediment parameters using multibeam acoustic data: a case study on the Carnavon Shelf, Western Australia. Int J Geogr Inf Sci 26:283-307

Huston MA (2002) Introductory essay: critical issues for improving predictions. In: Scott JM, Heglund PJ, Samson F, Haufler J, Morrison M, Raphael M, Wall B (eds) Predicting species occurrences: issues of accuracy and scale. Island Press, Washington DC, p 7-21

> Hutchinson GE, MacArthur RH (1959) A theoretical ecological model of size distributions among species of animals. Am Nat 93:117-125

> Jelinski D, Wu J (1996) The modifiable areal unit problem and implications for landscape ecology. Landsc Ecol 11: 129-140

Jombart T, Devillard S, Dufour AB, Pontier D (2008) Revealing cryptic patterns in genetic variability by a new multivariate method. Heredity 101:92-103

> Jones JB (1992) Environmental impact of trawling on the seabed: a review. NZ J Mar Freshw Res 26:59-67

Kaliontzopoulou A, Brito JC, Carretero MA (2008) Modelling the partially unknown distribution of wall lizards (Podarcis) in North Africa: ecological affinities, potential areas of occurrence, and methodological constraints. Can J Zool 86:992-1001

Katsanevakis S, Stelzenmüller V, South A, Sorensen TK and others (2011) Ecoystem-based marine spatial management: Review of concepts, policies, tools, and critical issues. Ocean Coast Manag 54:807-820

Keitt TH, Bjørnstad ON, Dixon PM, Citron-Pousty S (2002) Accounting for spatial pattern when modeling organismenvironment interactions. Ecography 25:616-625

Kendall MS, Miller TJ (2008) The influence of thematic and spatial resolution on maps of a coral reef ecosystem. Mar Geod 31:75-102

Kendall MS, Miller TJ (2010) Relationships among map resolution, fish assemblages, and habitat variables in a coral reef ecosystem. Hydrobiologia 637:101-119

Kendall MS, Miller TJ, Pittman SJ (2011) Patterns of scaledependency and the influence of map resolution on the seascape ecology of reef fish. Mar Ecol Prog Ser 427: 259-274

Kenny AJ, Cato I, Desprez M, Fader G, Schüttenhelm RTE, Side J (2003) An overview of seabed-mapping technologies in the context of marine habitat classification. ICES J Mar Sci 60:411-418

Kinlan BP, Gaines SD (2003) Propagule dispersal in marine and terrestrial environments: a community perspective. Ecology 84:2007-2020

Knobles DP, Wilson PS, Goff JA, Cho SE (2008) Seabed acoustics of a sand ridge on the New Jersey continental shelf. J Acoust Soc Am 124:EL151-EL156
Koslow JA, Boehlert GW, Gordon JDM, Haedrich RL, Lorance P, Parin N (2000) Continental slope and deepsea fisheries: implications for a fragile ecosystem. ICES J Mar Sci 57:548-557

Kostylev VE, Todd BJ, Fader GBJ, Courtney RC, Cameron GDM, Pickrill RA (2001) Benthic habitat mapping on the Scotian Shelf based on multibeam bathymetry, surficial geology and sea floor photographs. Mar Ecol Prog Ser 219:121-137

> Kristan WBI (2006) Sources and expectations for hierarchical structure in bird-habitat associations. Condor 108:5-12

> Kwasnitschka T, Hansteen TH, Devey CW, Kutterolf S (2013) Doing fieldwork on the seafloor: photogrammetric techniques to yield 3D visual models from ROV video. Comput Geosci 52:218-226

Laffan SW, Skidmore AK, Franklin J (2012) Geospatial analysis of species, biodiversity and landscapes: introduction to the second special issue on spatial ecology. Int J Geogr Inf Sci 26:2003-2007

- Laffan SW, Skidmore AK, Franklin J (2014) Species distribution and diversity, habitat selection and connectivity: introduction to the third special issue on spatial ecology. Int J Geogr Inf Sci 28:1527-1530

Larsen FW, Rahbek C (2005) The influence of spatial grain size on the suitability of the higher-taxon approach in continental priority-setting. Anim Conserv 8:389-396

> Latimer AM, Wu SS, Gelfand AE, Silander JA (2006) Building statistical models to analyze species distributions. Ecol Appl 16:33-50

> Leaper R, Dunstan PK, Foster SD, Barrett NJ, Edgar GJ (2012) Comparing large-scale bioregions and fine-scale community-level biodiversity predictions from subtidal rocky reefs across south-eastern Australia. J Appl Ecol 49:851-860

> Lechner AM, Langford WT, Bekessy SA, Jones SD (2012a) Are landscape ecologists addressing uncertainty in their remote sensing data? Landsc Ecol 27:1249-1261

> Lechner AM, Langford WT, Jones SD, Bekessy SA, Gordon A (2012b) Investigating species-environment relationships at multiple scales: differentiating between intrinsic scale and the modifiable areal unit problem. Ecol Complex 11:91-102

Lecours V, Devillers R (2015) Assessing the spatial data quality paradox in the deep-sea. In: Sieber RE (ed) Proceedings of Spatial Knowledge and Information - Canada (SKI-Canada) 2015, February 27-28, Banff, Alberta, p 1-8

Lecours V, Miles LL, Devillers R, Edinger EN (2013) Data analysis towards the multiscale characterization of coldwater coral and sponge habitats in Canadian waters. Tech Rep REQ. No. F6160-120010. Department of Fisheries and Oceans Canada, Newfoundland and Labrador Region, St. John's

Lecours V, Lucieer VL, Dolan MFJ, Micallef A (2015) An ocean of possibilities: applications and challenges of marine geomorphometry. In: Jasiewicz J, Zwoliński Z, Mitasova H, Hengl $\mathrm{T}$ (eds) Geomorphometry for geosciences. Bogucki Wydawnictwo Naukowe, Poznań, p 23-26

Legendre P (1993) Spatial autocorrelation: problem or new paradigm. Ecology 74:1659-1673

> Legendre L, Demers S (1984) Towards dynamic biological oceanography and limnology. Can J Fish Aquat Sci 41: $2-19$

> Legendre P, Fortin MJ (1989) Spatial pattern and ecological 
analysis. Vegetatio 80:107-138

Lennon JJ (2000) Red shifts and red herrings in geographical ecology. Ecography 23:101-113

Levin SA (1989) Challenges in the development of a theory of ecosystem structure and function. In: Roughgarden J, May RM, Levin SA (eds) Perspectives in ecological theory. Princeton University Press, Princeton, NJ, p 242-255

> Levin SA (1992) The problem of pattern and scale in ecology. Ecology 73:1943-1983

> Levin LA, Dayton PK (2009) Ecological theory and continental margins: where shallow meets deep. Trends Ecol Evol 24:606-617

Li Z (2008) Multi-scale terrain modelling and analysis. In: Zhou Q, Lees B, Tang GA (eds) Advances in digital terrain analysis. Springer, Berlin, p 59-83

Lloyd CD (2010a) Analysing population characteristics using geographically weighted principal component analysis: a case study of Northern Ireland in 2001. Comput Environ Urban Sys 34:389-399

Lloyd CD (2010b) Exploring population spatial concentrations in Northern Ireland by community background and other characteristics: an application of geographically weighted spatial statistics. Int J Geogr Inf Sci 24: 1193-1221

Lloyd CD (2014) Exploring spatial scale in geography. WileyBlackwell, Chichester

> Lourie SA, Vincent ACJ (2004) Using biogeography to help set priorities in marine conservation. Conserv Biol 18: 1004-1020

Lu B, Charlton M, Harris P, Fotheringham AS (2014a) Geographically weighted regression with a non-Euclidean distance metric: a case study using hedonic house price data. Int J Geogr Inf Sci 28:660-681

Lu B, Harris P, Gollini I, Charlton M, Brunsdon C (2014b) The GWmodel R package: further topics for exploring spatial heterogeneity using geographically weighted models. Geospatial Inform Sci 17:85-101

> Lucieer V, Hill NA, Barrett NS, Nichol S (2013) Do marine substrates 'look' and 'sound' the same? Supervised classification of multibeam acoustic data using autonomous underwater vehicle images. Estuar Coast Shelf Sci 117: 94-106

Lüdtke A, Jerosch K, Herzog O, Schlüter M (2012) Development of a machine learning technique for automatic analysis of seafloor image data: Case example, Pogonophora coverage at mud volcanoes. Comput Geosci 39:120-128

MacMillan RA, Shary PA (2009) Landforms and landform elements in geomorphometry. In: Hengl $\mathrm{T}$, Reuter HI (eds) Geomorphometry: concepts, software, applications. (Developments in soil science 33). Elsevier Science, Amsterdam, p 227-254

Maina J, Venus V, McClanahan TR, Ateweberhan M (2008) Modelling susceptibility of coral reefs to environmental stress using remote sensing data and GIS models. Ecol Model 212:180-199

> Marceau DJ (1999) The scale issue in social and natural sciences. Can J Rem Sens 25:347-356

> Marceau DJ, Hay GJ (1999) Remote sensing contributions to the scale issue. Can J Rem Sens 25:357-366

> Marsh L, Copley JT, Huvenne VAI, Tyler PA, Isis ROV Facility (2013) Getting the bigger picture: using precision Remotely Operated Vehicle (ROV) videography to acquire high-definition mosaic images of newly discovered hydrothermal vents in the Southern Ocean. DeepSea Res II 92:124-135
Mateo Sánchez MC, Cushman SA, Saura S (2014) Scale dependence in habitat selection: the case of the endangered brown bear (Ursus arctos) in the Cantabrian Range (NW Spain). Int J Geogr Inf Sci 28:1531-1546

> Mayor SJ, Schneider DC, Schaefer JA, Mahoney SP (2009) Habitat selection at multiple scales. Ecoscience 16: 238-247

McArthur MA, Brooke B, Przeslawski R, Ryan DA and others (2009) A review of surrogates for marine benthic biodiversity. Geoscience Australia Record 2009/42, Geoscience Australia, Canberra

> McArthur MA, Brooke B, Przeslawski R, Ryan DA and others (2010) On the use of abiotic surrogates to describe marine benthic biodiversity. Estuar Coast Shelf Sci 88: 21-32

McCoy ED, Bell SS, Mushinsky HR (1991) Habitat structure: synthesis and perspectives. In: Bell SS, McCoy ED, Mushinsky HR (eds) Habitat structure: the physical arrangement of objects in space. Chapman \& Hall, London, p 427-430

McLeod I, Skewes TD, Gordon SR, Pitcher CR (2007) A method for seabed habitat mapping: integrating acoustic information with biogeophysical observations; case study - Scott Reef. In: Todd BJ, Greene HG (eds) Mapping the seafloor for habitat characterization. Geol Assoc Can Spec Pap 47:309-317

Meentemeyer V (1989) Geographical perspectives of space, time, and scale. Landsc Ecol 3:163-173

Meentemeyer V, Box EO (1987) Scale effects in landscape studies. In: Turner MG (ed) Landscape heterogeneity and disturbance. Ecol Stud 64:15-34

Mellin C, Delean S, Caley J, Edgar G and others (2011) Effectiveness of biological surrogates for predicting patterns of marine biodiversity: a global meta-analysis. PLoS ONE 6:e20141

Mengerink KJ, Van Dover CL, Ardron J, Baker M and others (2014) A call for deep-ocean stewardship. Science 344: 696-698

Menke SB, Holway DA, Fisher RN, Jetz W (2009) Characterizing and predicting species distributions across environments and scales: Argentine ant occurrences in the eye of the beholder. Glob Ecol Biogeogr 18:50-63

> Meyer CB, Thuiller W (2006) Accuracy of resource selection functions across spatial scales. Divers Distrib 12:288-297

> Miller JA (2012) Species distribution models: spatial autocorrelation and non-stationarity. Prog Phys Geogr 36: 681-692

Miller JA, Hanham RQ (2011) Spatial nonstationarity and the scale of species-environment relationships in the Mojave Desert, California, USA. Int J Geogr Inf Sci 25: 423-438

Miller J, Franklin J, Aspinall R (2007) Incorporating spatial dependence in predictive vegetation models. Ecol Model 202:225-242

> Mizon GE (1995) A simple message for autocorrelation correctors: don't. J Econom 69:267-289

Moran P (1948) The interpretation of statistical maps. J R Stat Soc B 10:243-251

Moudrý V, Šímová P (2012) Influence of positional accuracy, sample size and scale on modelling species distributions: a review. Int J Geogr Inf Sci 26:2083-2095

Mumby PJ (2006) Connectivity of reef fish between mangroves and coral reefs: algorithms for the design of marine reserves at seascapes scales. Biol Conserv 128: $215-222$ 
Mumby PJ, Broad K, Brumbaugh DR, Dahlgren CP and others (2008) Coral reef habitats as surrogates of species, ecological functions, and ecosystem services. Conserv Biol 22:941-951

> Munday PL, Jones GP, Caley MJ (1997) Habitat specialisation and the distribution and abundance of coraldwelling gobies. Mar Ecol Prog Ser 152:227-239

- Muñoz-Reinoso JC (2009) Boundaries and scales in shrublands of the Doñana biological reserve, Southwest Spain. Landscape Ecol 24:509-518

Muotka T, Mäki-Petäys A, Kreivi P, Högmander H (1998) Spatial associations between lotic fish, macroinvertebrate prey and the stream habitat: a multi-scale approach. Boreal Environ Res 3:371-380

Nash KL, Allen CR, Angeler DG, Barichievy C and others (2014) Discontinuities, cross-scale patterns, and the organization of ecosystems. Ecology 95:654-667

> Nelson A (2001) Analysing data across geographic scales in Honduras: detecting levels of organisation within systems. Agric Ecosyst Environ 85:107-131

> Olsgard F, Schaanning MT, Widdicombe S, Kendall MA, Austen MC (2008) Effects of bottom trawling on ecosystem functioning. J Exp Mar Biol Ecol 366:123-133

Openshaw S (1984) The modifiable areal unit problem. CATMOG - Concepts and Techniques in Modern Geography, Vol. 38. Geo Books, Norwich

Openshaw S, Taylor PJ (1979) A million or so correlation coefficients: three experiments on the modifiable areal unit problem. In: Wrigley N (ed) Statistical applications in the spatial sciences. Pion, London, p 127-144

> Owen M (1972) Some factors affecting food intake and selection in white-fronted geese. J Anim Ecol 41:79-92

> Oyana TJ, Achenie LEK, Heo J (2012) The new and computationally efficient MIL-SOM algorithm: potential benefits for visualization and analysis of a large-scale high-dimensional clinically acquired geographic data. Comput Math Methods Med 2012:683265

> Pandit SN, Kolasa J, Cottenie K (2009) Contrasts between habitat generalists and specialists: an empirical extension to the basic metacommunity framework. Ecology 90 : 2253-2262

Pardo-Igúzquiza E, Dowd PA (2002) FACTOR2D: A computer program for factorial cokriging. Comput Geosci 28: $857-875$

Pearson SM (2002) Interpreting landscape patterns from organism-based perspectives. In: Gergel SE, Turner MG (eds) Learning landscape ecology. Springer, New York, NY, p 187-198

Pearson RG, Dawson TP (2003) Predicting the impacts of climate change on the distribution of species: are bioclimate envelope models useful? Glob Ecol Biogeogr 12: 361-371

> Peterson AT, Nakazawa Y (2008) Environmental data sets matter in ecological niche modelling: an example with Solenopsis invicta and Solenopsis richteri. Glob Ecol Biogeogr 17:135-144

Peterson AT, Soberón J, Pearson RG, Anderson RP, Martínez-Meyer E, Nakamura M, Araújo MB (2011) Ecological niches and geographic distributions. Monogr Popul Biol 49

> Pittman SJ, Brown KA (2011) Multi-scale approach for predicting fish species distributions across coral reef seascapes. PLoS ONE 6:e20583

Pittman SJ, McAlpine CA (2003) Movements of marine fish and decapod crustaceans: process, theory and applica- tion. Adv Mar Biol 44:205-294

Pittman SJ, Caldow C, Hile SD, Monaco ME (2007) Using seascape types to explain the spatial patterns of fish in the mangroves of SW Puerto Rico. Mar Ecol Prog Ser 348: 273-284

Pittman SJ, Costa BM, Battista TA (2009) Using LiDAR bathymetric and boosted regression trees to predict the diversity and abundance of fish and corals. J Coast Res Spec Issue 53:27-38

> Pittman SJ, Kneib RT, Simenstad CA (2011) Practicing coastal seascape ecology. Mar Ecol Prog Ser 427:187-190

> Pogson M, Smith P (2015) Effect of spatial data resolution on uncertainty. Environ Model Softw 63:87-96

> Prados R, Garcia R, Gracias N, Escartín J, Neumann L (2012) A novel blending technique for underwater gigamosaicing. IEEE J Oceanic Eng 37:626-644

> Preston J (2009) Automated acoustic seabed classification of multibeam images of Stanton Banks. Appl Acoust 70: 1277-1287

> Puig P, Canals M, Company JB, Martín J and others (2012) Ploughing the deep sea floor. Nature 489:286-289

> Purkis SJ, Kohler KE (2008) The role of topography in promoting fractal patchiness in a carbonate shelf landscape. Coral Reefs 27:977-989

Purser A, Bergmann M, Lundälv T, Ontrup J, Nattkemper TW (2009) Use of machine-learning algorithms for the automated detection of cold-water coral habitats: a pilot study. Mar Ecol Prog Ser 397:241-251

Rahbek C, Graves GR (2001) Multiscale assessment of patterns of avian species richness. Proc Natl Acad Sci USA 98:4534-4539

> Ramirez-Llodra E, Tyler PA, Baker MC, Aksel Bergstad O and others (2011) Man and the last great wilderness: Human impact on the deep sea. PLoS ONE 6:e22588

> Rengstorf AM, Grehan A, Yesson C, Brown C (2012) Towards high-resolution habitat suitability modeling of vulnerable marine ecosystems in the deep-sea: resolving terrain attribute dependencies. Mar Geod 35:343-361

Rengstorf AM, Yesson C, Brown C, Grehan AJ (2013) Highresolution habitat suitability modelling can improve conservation of vulnerable marine ecosystems in the deep sea. J Biogeogr 40:1702-1714

> Reside AE, Watson I, VanDerWal J (2011) Incorporating lowresolution historic species location data decreases performance of distribution models. Ecol Model 222: 3444-3448

Rex MA, Etter RJ (2010) Deep-sea biodiversity: pattern and scale. Harvard University Press, Cambridge, MA

Rigby P, Pizarro O, Williams SB (2010) Toward adaptive benthic habitat mapping using Gaussian process classification. J Field Robot 27:741-758

> Roberts JM, Henry LA, Long D, Hartley JP (2008) Coldwater coral reef frameworks, megafaunal communities and evidence for coral carbonate mounds on the Hatton Bank, north east Atlantic. Facies 54:297-316

$>$ Robinson WS (1950) Ecological correlation and the behavior of individuals. Am Sociol Rev 15:351-357

> Robinson LM, Elith J, Hobday AJ, Pearson RG, Kendall BE, Possingham HP, Richardson AJ (2011) Pushing the limits in marine species distribution modelling: lessons from the land present challenges and opportunities. Glob Ecol Biogeogr 20:789-802

> Rocchini D, Hortal J, Lengyel S, Lobo JM and others (2011) Accounting for uncertainty when mapping species distributions: the need for maps of ignorance. Prog Phys 
Geogr 35:211-226

Roff JC, Taylor ME, Laughren J (2003) Geophysical approaches to the classification, delineation and monitoring of marine habitats and their communities. Aquat Conserv 13:77-90

Ross RE, Howell KL (2013) Use of predictive habitat modelling to assess the distribution and extent of the current protection of 'listed' deep-sea habitats. Divers Distrib 19: 433-445

Sarkar S, Justus J, Fuller T, Kelley C, Garson J, Mayfield M (2005) Effectiveness of environmental surrogates for the selection of conservation area networks. Conserv Biol 19: 815-825

Saura S (2002) Effects of minimum mapping unit on land cover data spatial configuration and composition. Int J Remote Sens 23:4853-4880

Schimel ACG, Healy TR, Johnson D, Immenga D (2010) Quantitative experimental comparison of single-beam, sidescan, and multibeam benthic habitat maps. ICES J Mar Sci 67:1766-1779

Schmidt J, Andrew R (2005) Multi-scale landform characterization. Area 37:341-350

Schneider DC (2001a) The rise of the concept of scale in ecology. Bioscience 51:545-553

Schneider DC (2001b) Concepts and effects of scale. In: Levin SA (ed) Encyclopedia of Biodiversity. Academic Press, San Diego, CA, p 245-254

Schneider DC (1994) Quantitative ecology: spatial and temporal scaling. Academic Press, San Diego, CA

Schneider DC (2009) Quantitative ecology, 2nd edn: measurements, models and scaling. Academic Press, San Diego, CA

Schneider DC, Haedrich RL (1991) Post-mortem erosion of fine-scale spatial structure of epibenthic megafauna on the outer Grand Bank of Newfoundland. Cont Shelf Res 11:1223-1236

Schneider DC, Gagnon JM, Gilkinson KD (1987) Patchiness of epibenthic megafauna on the outer Grand Banks of Newfoundland. Mar Ecol Prog Ser 39:1-13

Schoch GC, Dethier MN (1996) Scaling up: the statistical linkage between organismal abundance and geomorphology on rocky intertidal shorelines. J Exp Mar Biol Ecol 201:37-72

Segurado P, Araújo MB, Kunin WE (2006) Consequences of spatial autocorrelation for niche-based models. J Appl Ecol 43:433-444

Seiler J, Friedman A, Steinberg D, Barrett N, Williams A, Holbrook NJ (2012) Image-based continental shelf habitat mapping using novel automated data extraction techniques. Cont Shelf Res 45:87-97

Seo C, Thorne JH, Hannah L, Thuiller W (2009) Scale effects in species distribution models: implication for conservation planning under climate change. Biol Lett 5:39-43

Shary PA, Sharava LS, Mitusov AV (2002) Fundamental quantitative methods of land surface analysis. Geoderma 107:1-32

Sherry TW, Holmes RT (1988) Habitat selection by breeding American redstarts in response to a dominant competitor, the least flycatcher. Auk 105:350-364

Shucksmith RJ, Kelly C (2014) Data collection and mapping - principles, processes and application in marine spatial planning. Mar Policy 50:27-33

Skidmore AK, Franklin J, Dawson TP, Pilesjö P (2011) Geospatial tools address emerging issues in spatial ecology: a review and commentary on the special issue. Int $\mathrm{J}$
Geogr Inf Sci 25:337-365

Smith PA (1994) Autocorrelation in logistic regression modelling of species' distribution. Glob Ecol Biogeogr 4: 47-61

Smith G, Brennan RE (2012) Losing our way with mapping: Thinking critically about marine spatial planning in Scotland. Ocean Coast Manag 69:210-216

Snickars M, Gullström M, Sundblad G, Bergström U, Downie AL, Lindegarth M, Mattila J (2014) Speciesenvironment relationships and potential for distribution modelling in coastal waters. J Sea Res 85:116-125

Sokal RR (1979) Ecological parameters inferred from spatial correlograms. In: Patil GP, Rosenzwig ML (eds) Contemporary quantitative ecology and related ecometrics. International Co-operative Publishing House, Fairland, MD, p 167-196

Sokal RR, Oden NL (1978) Spatial autocorrelation in biology: some biological implications and four applications of evolutionary and ecological interest. Biol J Linn Soc 10: 229-249

Solan M, Germano JD, Rhoads DC, Smith C and others (2003) Towards a greater understanding of pattern, scale and process in marine benthic systems: a picture is worth a thousand worms. J Exp Mar Biol Ecol 285-286:313-338

Steele JH (1978) Some comments on plankton patches. In: Steele JH (ed) Spatial pattern in plankton communities. Plenum Press, New York, NY, p 1-20

Steele JH (1991) Can ecological theory cross the land-sea boundary? J Theor Biol 153:425-436

Stommel H (1963) The varieties of oceanographic experience. Science 139:572-576

> Stone KH (1972) A geographer's strength: the multiple scales approach. J Geog 71:354-362

Stone RP (2006) Coral habitat in the Aleutian Islands of Alaska: depth distribution, fine-scale species associations, and fisheries interactions. Coral Reefs 25:229-238

Store R, Jokimäki J (2003) A GIS-based multi-scale approach to habitat suitability modeling. Ecol Model 169:1-15

Synes NW, Osborne PE (2011) Choice of predictor variables as a source of uncertainty in continental-scale species distribution modelling under climate change. Glob Ecol Biogeogr 20:904-914

Tabachnick BG, Fidell LS (2013) Using multivariate statistics, 6th edn. Pearson Education Limited, Harlow

Tanner JE, Mellin C, Parrott L, Bradshaw CJA (2015) Finescale biodiversity patterns inferred from image processing. Ecol Complex 22:76-85

- Thrush SF, Dayton PK (2002) Disturbance to marine benthic habitats by trawling and dredging: implications for marine biodiversity. Annu Rev Ecol Syst 33:449-473

Thurber AR, Sweetman AK, Narayanaswamy BE, Jones DOB, Ingels J, Hansman RL (2013) Ecosystem function and services provided by the deep sea. Biogeosciences Discuss 10:18193-18240

Tissot BN, Yoklavich MM, Love MS, York K, Amend M (2006) Benthic invertebrates that form habitat on deep banks off southern California, with special reference to deep sea coral. Fish Bull 104:167-181

Tittensor DP, Baco AR, Brewin PE, Clark MR and others (2009) Predicting global habitat suitability for stony corals on seamounts. J Biogeogr 36:1111-1128

Tobler WR (1970) A computer movie simulating urban growth in the Detroit region. Econ Geogr 46:234-240

Todd BJ, Greene HG (eds) (2007) Mapping the seafloor for habitat characterization. Geol Assoc Can Spec Pap 47 
Tong R, Purser A, Guinan J, Unnithan V (2013) Modeling the habitat suitability of deep-water gorgonian corals based on terrain variables. Ecol Inform 13:123-132

Turner MG, Gardner RH, O'Neill RV (2001) Landscape ecology, in theory and practice: pattern and process. Springer-Verlag, New York, NY

Turner W, Rondinini C, Pettorelli N, Mora B and others (2015) Free and open-access satellite data are key to biodiversity conservation. Biol Conserv 182:173-176

Urban DL, O'Neill RV, Shugart HH Jr (1987) Landscape ecology. Bioscience 37:119-127

Václavík T, Kupfer JA, Meentemeyer RK (2012) Accounting for multi-scale spatial autocorrelation improves performance of invasive species distribution modelling (iSDM). J Biogeogr 39:42-55

> Van Rein HB, Brown CJ, Quinn R (2009) A review of sublittoral monitoring methods in temperate waters: a focus on scale. Underw Technol 28:99-113

> VanDerWal J, Shoo LP, Graham C, Williams SE (2009) Selecting pseudo-absence data for presence-only distribution modeling: How far should you stray from what you know? Ecol Model 220:589-594

> VanderWerf EA (1993) Scales of habitat selection by foraging 'elepaio in undisturbed and human-altered forests in Hawaii. Condor 95:980-989

Veloz SD (2009) Spatially autocorrelated sampling falsely inflates measures of accuracy for presence-only niche models. J Biogeogr 36:2290-2299

Verfaillie E, Du Four I, Van Meirvenne M, Van Lancker V (2009) Geostatistical modeling of sedimentological parameters using multi-scale terrain variables: application along the Belgian part of the North Sea. Int J Geogr Inf Sci 23:135-150

Vierod ADT, Guinotte JM, Davies AJ (2014) Predicting the distribution of vulnerable marine ecosystems in the deep sea using presence-background models. Deep-Sea Res II 99:6-18

> Ward TJ, Vanderklift MA, Nicholls AO, Kenchington RA (1999) Selecting marine reserves using habitats and species assemblages as surrogates for biological diversity. Ecol Appl 9:691-698

Wedding LM, Friedlander AM (2008) Determining the influence of seascape structure on coral reef fishes in Hawaii using a geospatial approach. Mar Geod 31:246-266

> Wedding LM, Friedlander AM, McGranaghan M, Yost RS, Monaco ME (2008) Using bathymetric LiDAR to define nearshore benthic habitat complexity: implications for management of reef fish assemblages in Hawaii. Remote Sens Environ 112:4159-4165

Wedding LM, Lepczyk CA, Pittman SJ, Friedlander AM, Jorgensen S (2011) Quantifying seascape structure: extending terrestrial spatial pattern metrics to the marine realm. Mar Ecol Prog Ser 427:219-232

Wheatley M, Johnson C (2009) Factors limiting our understanding of ecological scale. Ecol Complex 6:150-159

Whitmire CE, Embley RW, Wakefield WW, Merle SG, Tissot BN (2007) A quantitative approach for using multibeam sonar data to map benthic habitats. In: Todd BJ, Greene HG (eds) Mapping the seafloor for habitat characterization. Geol Assoc Can Spec Pap 47:111-126

Whittaker RH, Levin SA, Root RB (1973) Niche, habitat, and

Editorial responsibility: Christine Paetzold, Oldendorf/Luhe, Germany ecotope. Am Nat 107:321-338

Wiens JA (1989) Spatial scaling in ecology. Funct Ecol 3: 385-397

Wiens JA, Addicott JF, Case TJ, Diamond J (1986a) Overview: the importance of spatial and temporal scale in ecological investigations. In: Diamond J, Case TJ (eds) Community ecology. Harper \& Row, New York, NY, p 145-153

> Wiens JA, Rotenberry JT, Van Horne B (1986b) A lesson in the limitations of field experiments: shrubsteppe birds and habitat alteration. Ecology 67:365-376

Williams A, Schlacher TA, Rowden AA, Althaus F and others (2010) Seamount megabenthic assemblages fail to recover from trawling impacts. Mar Ecol 31:183-199

> Williams KJ, Belbin L, Austin MP, Stein JL, Ferrier S (2012) Which environmental variables should I use in my biodiversity model? Int J Geogr Inf Sci 26:2009-2047

Willis KJ, Whittaker RJ (2002) Species diversity — scale matters. Science 295:1245-1248

> Wilson MFJ, O'Connell B, Brown C, Guinan JC, Grehan AJ (2007) Multiscale terrain analysis of multibeam bathymetry data for habitat mapping on the continental slope. Mar Geod 30:3-35

Windle MJS, Rose GA, Devillers R, Fortin MJ (2010) Exploring spatial non-stationarity of fisheries survey data using geographically weighted regression (GWR): an example from the Northwest Atlantic. ICES J Mar Sci 67:145-154

- Windle MJS, Rose GA, Devillers R, Fortin MJ (2012) Spatiotemporal variations in invertebrate-cod-environment relationships on the Newfoundland-Labrador Shelf, 1995-2009. Mar Ecol Prog Ser 469:263-278

With KA, King AW (1997) The use and misuse of neutral landscape models in ecology. Oikos 79:219-229

Wright DJ (1999) Getting to the bottom of it: tools, techniques, and discoveries of deep ocean geography. Prof Geogr 51:426-439

- Wright D, Goodchild MF (1997) Data from the deep: implications for the GIS community. Int J Geogr Inf Sci 11: 523-528

> Wu J (1999) Hierarchy and scaling: extrapolating information along a scaling ladder. Can J Rem Sens 25:367-380

Wu J, Gao W, Tueller PT (1997) Effects of changing spatial scale on the results of statistical analysis with landscape data: a case study. Geogr Inf Sci 3:30-41

> Wu XB, Smeins FE (2000) Multiple-scale habitat modeling approach for rare plant conservation. Landsc Urban Plan 51:11-28

Young CM (2009) Communities on deep-sea hard bottoms. In: Wahl M (ed) Marine hard bottom communities: patterns, dynamics, diversity, and change. Springer, Berlin, p 39-60

Zajac R (2008) Challenges in marine, soft-sediment benthoscape ecology. Landscape Ecol 23:7-18

Zhang J, Atkinson PM, Goodchild MF (2014) Scale in spatial information and analysis. CRC Press, Boca Raton, FL

Zieger S, Stieglitz T, Kininmonth S (2009) Mapping reef features from multibeam sonar data using multiscale morphometric analysis. Mar Geol 264:209-217

Zimmermann NE, Edwards TC, Graham CG, Pearman PB, Svenning JC (2010) New trends in species distribution modelling. Ecography 33:985-989

Submitted: October 8, 2014; Accepted: May 29, 2015

Proofs received from author(s): August 19, 2015 